\title{
3 Research Square

\section{Integrated optimization of structure and control parameters for the height control system of a vertical spindle cotton picker}

\section{Xingzheng Chen}

Southwest University

Congbo Li ( $\square$ congboli@cqu.edu.cn )

Chongqing University

Rui Hu

Chongqing University

Ning Liu

National University of Singapore

Chi Zhang

Chongqing University

\section{Original Article}

Keywords: Cotton picker, Height control system, Structure parameters, Control parameters, Integrated optimization

Posted Date: June 18th, 2020

DOl: https://doi.org/10.21203/rs.3.rs-36296/v1

License: @ (i) This work is licensed under a Creative Commons Attribution 4.0 International License. Read Full License

Version of Record: A version of this preprint was published at Chinese Journal of Mechanical Engineering on December 1st, 2021. See the published version at https://doi.org/10.1186/s10033-021-00662-4. 


\section{Title page}

\section{Integrated Optimization of Structure and Control Parameters for the Height Control System of a Vertical Spindle Cotton Picker}

Xing-Zheng Chen, born in 1990, is currently a Lecturer at College of Engineering and Technology, Southwest University. He received his Ph.D degree from Chongqing University, China, in 2018. His research interests include on electronic-hydraulic system optimization and energy efficient machining.

E-mail: chenxzh@swu.edu.cn

Cong Bo-Li, born in 1981, is currently a Professor at State Key Laboratory of Mechanical Transmission, Chongqing University, China. His main research interests include modeling and optimization control, green manufacturing, energy efficient manufacturing and remanufacturing.

E-mail: congboli@cqu.edu.cn

Rui-Hu, born in 1994, is currently a master candidate at State Key Laboratory of Mechanical Transmission, Chongqing University, China.

E-mail: hbhr0618@cqu.edu.cn

Ning-Liu, born in 1989, is currently a Research Fellow at Department of Mechanical Engineering, National University of Singapore, Singapore. His research interests include artificial intelligence for industrial solutions, metallic additive manufacturing and industrial automation.

E-mail: liuning@u.nus.edu

Chi-Zhang, born in 1995, is currently a master candidate at State Key Laboratory of Mechanical Transmission, Chongqing University, China.

E-mail: 13678418764@163.com

\section{Corresponding author: Cong Bo-Li E-mail: congboli@cqu.edu.cn}




\title{
Integrated Optimization of Structure and Control Parameters for the Height Control System of a Vertical Spindle Cotton Picker
}

\author{
Xing-Zheng Chen ${ }^{1} \cdot$ Cong-Bo $\mathrm{Li}^{2} \cdot$ Rui Hu${ }^{2} \cdot \mathrm{Ning} \mathrm{Liu}^{3} \cdot \mathrm{Chi}^{\mathrm{Zhang}}{ }^{2}$
}

Received June xx, 2020; revised February xx, 202x; accepted March xx, 202x

(c) Chinese Mechanical Engineering Society and Springer-Verlag Berlin Heidelberg 2017

\begin{abstract}
'Abstract: Vertical picking method is a predominate method used to harvest cotton crop. However, a vertical picking method may cause spindle bending of the cotton picker if spindles collide with stones on the cotton field. Thus, how to realize a precise height control of the cotton picker is a crucial issue to be solved. The objective of this study is to design a height control system to avoid the collision. To design it, the mathematical models are established first. Then a multi-objective optimization model represented by structure parameters and control parameters is proposed to take the pressure of chamber without piston, response time and displacement error of the height control system as the optimization objectives. An integrated optimization approach that combines optimization via simulation, particle swarm optimization and simulated annealing is proposed to solve the model. Simulation and experimental test results show that the proposed integrated optimization approach can not only reduce the pressure of chamber without piston, but also decrease the response time and displacement error of the height control system.
\end{abstract}

Keywords: Cotton picker - Height control system - Structure parameters $\bullet$ Control parameters $\bullet$ Integrated optimization

\section{Introduction}

Cotton is one of the most important crops [1]. According to the data from International Cotton Advisory Committee, the world

$\triangle$ Cong-Bo Li

congboli@cqu.edu.cn

1 College of Engineering and Technology, Southwest University, Chongqing 400715, China

2 State Key Laboratory of Mechanical Transmission, Chongqing University, Chongqing 400044, China

3 Department of Mechanical Engineering, National University of Singapore, Singapore 119077, Singapore cotton production was estimated to increase to 25.74 million tons in 2018. Increasing cotton production creates an urgent need for high efficiency harvesting machines. Due to the high efficiency in cotton harvesting, in recent years, the mechanical cotton pickers have gained more and more application. Among these mechanical cotton pickers, the most representative one is the horizontal spindle cotton pickers produced by John Deere and CaseIH, which can work not only reliably and stably, but also harvest with low cotton loss and less cotton leaf [2].

However, during the cotton harvesting process, the traditional horizontal spindle cotton picker is parallel to the cotton crop, which may lead to a low fiber quality of the cotton. To solve this problem, vertical spindle cotton pickers are developed in recent years. It adopts a telescopic cotton removal method to avoid the reverse pulling by the cotton removal tray, which can efficiently improve the cotton fiber quality. Nevertheless, when using the vertical spindle cotton pickers, the spindles of cotton pickers may touch the soil. This may cause a deformation of spindles and decreasing the cotton picking efficiency. Therefore, it is important to develop a height control system for the vertical spindle cotton picker, with which the vertical spindle cotton picker can effectively adjust the height of the spindle according to different landform.

Usually, there are two kinds of height control system, i.e., mechanical height control system and electro-hydraulic height control system. In early agricultural practice, the mechanical height control system is widely used in the no-till seeding $[3,4]$ and transplanting machines [5] due to its simple structure, easy control logic and low cost. With the mechanical height control system, the seeding and transplanting efficiency can be efficiently improved [6-8]. Unfortunately, as the control accuracy and response time of the mechanical height control system are poor, it cannot be used in cases that need high control accuracy and rapid response. To solve this problem, electro-hydraulic height control 
systems are developed by researchers [9-10].

However, although the electro-hydraulic height control system has higher control accuracy than the mechanical height control system, the control of its hydraulic cylinder is very complex. In the past, many researchers have been engaged in this area and a variety of control methods have been proposed to precisely control the electro-hydraulic height control system, such as proportion-integration-differentiation (PID) control algorithm [11], sliding-mode fuzzy control method [12], etc. Among these methods, PID control algorithm is widely used because of its features of simplicity, robustness and reliability [13]. Many improved PID algorithms are proposed based on the basic PID to enhance the probability of the suitable selection of the controller gains [14]. For example, in the work presented by Çetin and Akkaya, they combined traditional PID with fuzzy control algorithm for displacement controlling of hydraulic cylinder due to its strong adaptability for uncertain and nonlinear controlled objects [15].

A difficulty in a fuzzy PID control method is the design of fuzzy rules because it highly depends on the experience of experts or large amounts of experimental data [16]. Hence, the combinations with various nature-inspired optimization algorithms (NIOAs) have a significant impact on the performance of PID control. Other researchers used the NIOAs to optimize PID parameters and fuzzy controller, which can improve the control efficiency of the system. Examples of the approaches can be found in the works reported in References [17-20], such as Grey Wolf Optimizer algorithm [17], Particle Swarm Optimization [18, 19] and Simulated Annealing algorithm[20].

Summarizing the findings of the above discussion, it can be found that PID parameters have been optimized for hydraulic actuators to obtain accurate and precise control performance. However, the height control system of the cotton picker is a mechanical- electric-hydraulic coupled system. Its design should consider interactions between mechanical and electrical parts of the complete system [21]. Several works about integrated optimization approach have been carried out in the past decades, such as parallel robots [22], mesh reflector deployable space antennas [23], pipeline leak detection [24] and multistage synchronous induction coilgun [25]. It is confirmed that there is a lack of work in integrated optimization approach for the height control system.

Generally, for a height control system, its performance is dependent on its mechanical structure design and controller design. In designing such a system, the mechanical structure design cannot be optimized without considering its influence on control. Conversely, the control performance, which can be optimized by using control design methods, can further be improved by modifying the mechanical structure. Hence, optimization of mechanical structure parameters and control parameters in an integrated manner can further improve the performance of the height control system [26, 27]. Despite the success achieved by integrated optimization approach, little work has been devoted to height control system. Motivated by those findings, this paper aims to bridge the research gap and make the following contributions. Firstly, an integrated optimization model of mechanical structure parameters and control parameters is proposed to take the pressure of the chamber without piston, response time and displacement error of height control system as the optimization objectives. Secondly, this model is solved by Optimization via Simulation method (OvS), Particle Swarm Optimization (PSO) and Simulated Annealing (SA). To our best knowledge, it is the first time that both mechanical structure parameters and control parameters are simultaneously considered in the proposed integration problem for the height control system.

The rest of the paper is organized as follows. Section II presents the structure and working principle of the height control system. Section III establishes mathematical models of this system. Section IV presents an integrated optimization method. Section $\mathrm{V}$ gives the case study, followed by the conclusion in Section VI.

\section{Structure and Operating Principle of Height Control System}

\subsection{Structure of Height Control System}

Figure 1 shows the schematic of the proposed height control system, which consists of signal acquisition device, control system, hydraulic system and lifting mechanism. The signal of height is obtained via the angle sensor installed on the signal acquisition device. Then the signal of height is used to govern the electro-hydraulic servo valve. The hydraulic cylinder controlled by electro-hydraulic servo valve is used as the power sector of lifting mechanism. With cylinder controlled by valve to lift the spindles of the cotton picker, it can avoid spindles colliding with stones on the cotton field.

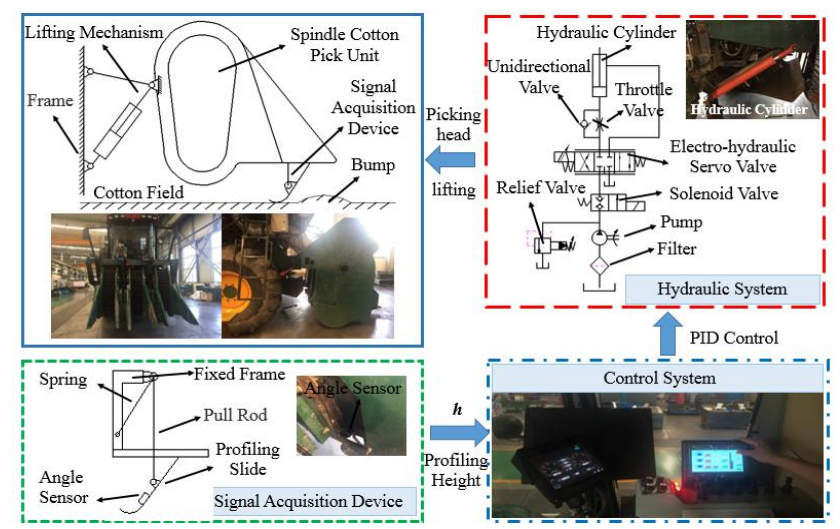

Figure 1 Schematic graph of the height control system 


\subsection{Principle of Operation}

\subsubsection{Signal Acquisition Device}

As shown in Figure 1, the signal acquisition device is installed on the picking unit. It mainly consists of an angle sensor, a profiling slider, a spring, a fixing frame and a pull rod. During the harvesting process, the profile slider is used to detect the height variation of soil surface. When it rotates, the angle sensor converts the angle change value into voltage signal, and transmits this signal to the control system. When the angle change of profiling slider is less than the minimum value of height set by the system preloading spring, the spring absorbs the angle change. Hence, the angle sensor does not detect angle changes and the height control system is negative. In this process, the preloading spring makes the profiling slider do not affect by small obstacles such as cotton bolls and cotton pole, and plays the role of protecting angle sensor. Furthermore, it makes the height control system more stable and reliable.

\subsubsection{Control System}

After the profiling height is obtained based on data collected by angle sensor, the voltage signal of profiling height is transmitted into the PID controller. Then the voltage signal is amplified by the servo amplifier and converted into the control current of the electro-hydraulic servo valve. The current signal is used to control the expansion and contraction of the piston of the hydraulic cylinder. Finally, the displacement sensor at the piston rod feeds back the displacement signal to the control system to form a closed-loop control to realize the accurate control of the hydraulic cylinder.

\subsubsection{Hydraulic System}

The hydraulic system of the height control system is shown in Figure 1. The solenoid valve is turned on and the fluid from the hydraulic pump flows into the electro-hydraulic servo valve. The PID control method is developed to control the opening size and direction of the electro-hydraulic servo valve. Hydraulic cylinders are one of the hydraulic action components, which are widely used to transfer hydraulic power produced by pump to mechanical power with the manner of straight movement. The pressure of the fluid control the oil cylinder up or down. It will control the height of the picking unit in real time, and ensure to adjust the height quickly and accurately. If the picking unit needs to maintain at a certain height, the solenoid valve will be closed to ensure a constant pressure of hydraulic system. When the hydraulic cylinder is unloaded, the function of the throttle valve is to provide back pressure for the hydraulic circuit, which can avoid the rapid drop of the picking unit.

\section{Mathematical Models}

\subsection{Modeling of the Lifting Mechanism}

The diagram of lifting mechanism of the height control system is shown in Figure 2. Line $A B$ represents the hydraulic cylinder. Point $B$ and point $C$ are articulated on the frame of the spindle cotton picker corresponding to the installation position. $L_{1}$ represents the total length of the hydraulic cylinder, $L_{2}$ is the length of articulated $\operatorname{rod} A C, L_{3}$ is the installation position on the frame, and $L_{4}$ is the distance of picking head centroid from articulated point $A$. $L_{1}$ can be further expressed as follows:

$$
L_{1}=L_{0}+L
$$

where $L_{0}$ and $L$ represent cylinder length and piston displacement of the hydraulic cylinder, respectively.

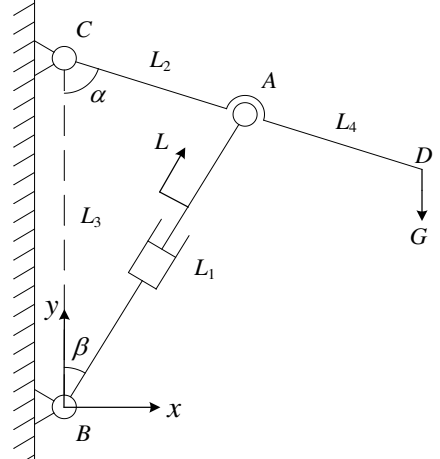

Figure 2 Schematic diagram of the lifting mechanism

For convenience of analyze the dynamics of the lifting mechanism, it is simplified to an equivalent diagram as shown in Figure 3. Then, the dynamic model of the equivalent lifting mechanism is formulated as follows:

$$
A_{1} P_{1}-A_{2} P_{2}=M \frac{\mathrm{d}^{2} L}{\mathrm{~d} t^{2}}+B \frac{\mathrm{d} L}{\mathrm{~d} t}+F_{L}
$$

where $A_{1}$ is the area of the end face of piston, $A_{2}$ is the effective area of the piston in cylinder chamber with piston, $A_{1}=\pi D^{2} / 4$ $A_{2}=\pi\left(D^{2}-d^{2}\right) / 4, D$ and $d$ are inner diameter of hydraulic cylinder and diameter of hydraulic cylinder piston, respectively. $P_{1}$ is the input oil pressure of the chamber without piston, $P_{2}$ is the pressure of chamber with piston. $M$ is the equivalent mass of the lifting mechanism. $t$ is the elapsed time of the lifting mechanism from starting to move to the end of lifting. $B$ is viscous damping coefficient of the piston, $F_{L}$ is the external load of the lifting mechanism.

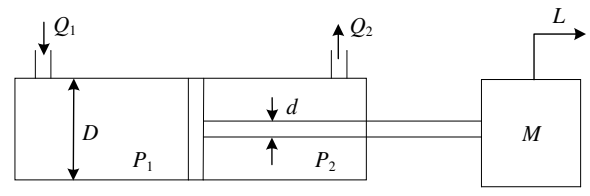

Figure 3 Equivalent model of the lifting mechanism 
Equivalent mass $M$ is calculated based on the theory that kinetic energy of the equivalent lifting mechanism is equal to the original lifting mechanism. Mass of hydraulic cylinder, piston and articulated rod $A C$ is negligible compared to the mass of picking unit. Besides, velocity of hydraulic cylinder, piston and articulated rod $A C$ is same order of magnitude with velocity of picking unit. So kinetic energy of hydraulic cylinder, piston and articulated rod $A C$ is ignored. Equivalent mass $M$ is calculated based on the following Eq.(3).

$$
\frac{1}{2} M \dot{L}^{2}=\frac{1}{2} m\left(\dot{x}^{2}+\dot{y}^{2}\right)
$$

where $m$ is the mass of picking unit, $m=G / g, G$ is gravitational force of picking unit, $g$ is gravitational acceleration; $\dot{x}$ and $\dot{y}$ are two components of barycenter velocity of picking unit. $x$ and $y$ are calculated as follows:

$$
\begin{gathered}
\left\{\begin{array}{l}
x=\left(L_{2}+L_{4}\right) \sin \alpha \\
y=L_{3}-\left(L_{2}+L_{4}\right) \cos \alpha
\end{array}\right. \\
\alpha=\arccos \left(\frac{L_{2}^{2}+L_{3}^{2}-L_{1}^{2}}{2 L_{2} L_{3}}\right)
\end{gathered}
$$

External load $F_{L}$ is calculated as shown in Eq.(6).

$$
F_{L}=G \frac{\mathrm{d} y}{\mathrm{~d} L}
$$

Based on Eqs.(1)-(6), the dynamic model of the equivalent lifting mechanism is expressed as follows:

$$
\begin{aligned}
\frac{\pi}{4} D^{2} P_{1}-\frac{\pi}{4}\left(D^{2}-d^{2}\right) P_{2}= & \frac{4 L_{1}^{2}\left(L_{2}+L_{4}\right)^{2}}{4 L_{2}^{2} L_{3}^{2}-\left(L_{2}^{2}+L_{3}^{2}-L_{1}^{2}\right)^{2}} \frac{G}{g} \frac{\mathrm{d}^{2} L}{\mathrm{~d} t^{2}}+B \frac{\mathrm{d} L}{\mathrm{~d} t} \\
& +\frac{G\left(L_{2}+L_{4}\right)\left(L_{0}+L\right)}{L_{2} L_{3}}
\end{aligned}
$$

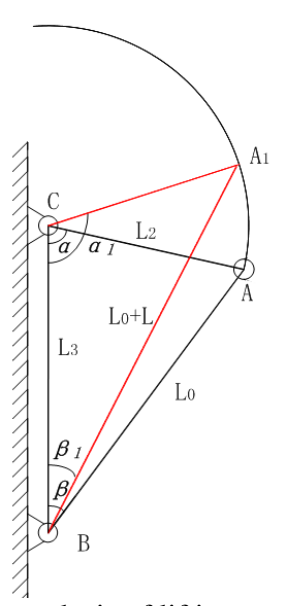

Figure 4 Kinematic analysis of lifting mechanism

The lifting mechanism of the height control system realizes the lifting function of the picking unit by extending the piston of the hydraulic cylinder. Thus, it can prevent the spindle from being bended in the collision with stones and metals. In Figure 4, point $A$ is the articulation of the hydraulic cylinder and the picking unit. When the articulation is in the state of point $A$, the picking unit works in the normal position. The piston of the hydraulic cylinder does not extend and its stroke is zero. When the piston of the hydraulic cylinder moves to point $A_{1}$, the picking unit is lifted. In this process, the profile height $h$ can be calculated as:

$$
h=\frac{L^{2}+2 L_{0} L}{2 L_{3}}
$$

When the surface of cotton field changes, the angle variation of profiling slider is detected by the angle sensor. The angle sensor transmits the angle variation into the controller. The controller will output signal to make the piston rod of the hydraulic cylinder extend. The profile height $h$ of the lifting mechanism is determined by the angle change of the angle sensor, which can be modelled as shown in Eq.(9).

$$
h=l \Delta \theta
$$

where $l$ is the distance between angle sensor and touchpoint of the profiling slide, $\Delta \theta$ is the angle change of angle sensor.

\subsection{Modeling of the Hydraulic Control System}

When the hydraulic fluid is pumped into the cylinder of the height control system, the hydraulic pressure will force the piston to move back and forth. The displacement and speed of the hydraulic cylinder is determined by the opening size of the electro-hydraulic servo valve. Therefore, the height and rising speed of the picking unit are adjusted by the electro-hydraulic servo valve. In order to achieve precise position tracking control, a PID controller, which is widely used in various industries due to its high reliability and robustness [28-31], is adopted to control the electro-hydraulic servo valve.

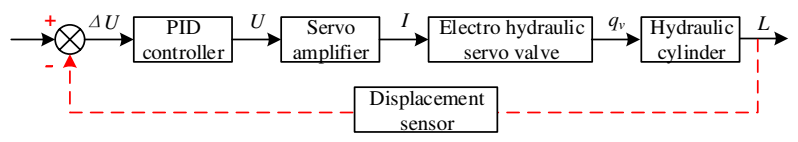

Figure 5 Control block diagram of hydraulic system.

As shown in Figure 5, the input of the PID controller is $\Delta U$, whose value is the difference between the actual displacement signal $U_{2}$ and the input displacement signal $U_{1}$. After a proportional, integral and differential processing of the PID controller, the new displacement signal $U$ is the output. Then the displacement signal $U$ is converted into control current $I$ of the electro-hydraulic servo valve by the servo amplifier. The transfer function of the servo amplifier is expressed in Eq.(10).

$$
\frac{I}{U}=\frac{K_{A} \omega_{A}}{s+\omega_{A}}
$$

where $K_{A}$ is the amplification factor of servo amplifier, $\omega_{A}$ is the 
natural frequency of the amplifier.

The control current $I$ of the electro-hydraulic servo valve controls the displacement of the valve core, thus resulting in the change of valve opening, and finally realizing the control of the flow $q_{v}$ of the electro-hydraulic servo valve. The transfer function of the electro-hydraulic servo valve is [32]:

$$
\frac{q_{v}}{I}=\frac{K_{s v} \omega_{s v}^{2}}{s^{2}+2 \xi_{s v} \omega_{s v} s+\omega_{s v}^{2}}
$$

where $K_{s v}$ is the gain of the electro-hydraulic servo valve, $\omega_{s v}$ is the natural frequency of the amplifier, $\xi_{s v}$ is the damping ratio of the electro-hydraulic servo valve.

When the output fluid of the electro-hydraulic servo valve flows into the hydraulic cylinder, the piston of the hydraulic cylinder will extend out of the cylinder block. So that the picking unit will be lifted to the position of the height required by the system. The transfer function of the hydraulic cylinder is:

$$
\frac{L}{q_{v}}=\frac{K_{h} \omega_{h}{ }^{2}}{s\left(s^{2}+2 \xi_{h} \omega_{h} s+\omega_{h}{ }^{2}\right)}
$$

where $K_{h}$ is the gain of hydraulic cylinder, $\omega_{h}$ is the natural frequency of hydraulic cylinder, $\xi_{h}$ is the damping ratio of hydraulic cylinder.

When the displacement $L$ of the piston rod is detected by the sensor installed on the hydraulic cylinder, it will be converted into actual displacement signal. The difference between the actual displacement signal and the input displacement signal are sent into the PID controller to adjust the displacement of the piston of the hydraulic cylinder. The transfer function of the displacement sensor is:

$$
\frac{U_{2}}{L}=\frac{K_{s e} \omega_{s e}}{s+\omega_{s e}}
$$

where $K_{s e}$ is the gain of displacement sensor, $\omega_{s e}$ is the natural frequency of displacement sensor.

\section{Multi-objective Optimization of Height Control System \\ The height control system is a} mechanics-electronics-hydraulics coupled system that consisting of signal acquisition device, control system, hydraulic system and lifting mechanism. For such a system, pressure in the chamber without piston, response time and displacement error are the most important performance indicators. A reduction of the pressure in the chamber without piston will decrease the pressure required by the hydraulic system and hence improve the reliability of the hydraulic system. Moreover, minimization the response time and displacement error can improve response speed and precision of the height control system. As a result, the probability of the spindle cotton picker, whose off-ground height can be adjusted by the height control system, colliding to the ground will be reduced. Hence, in order to reduce pressure in the chamber without piston and minimize response time and displacement error of the hydraulic system, a multi-objective optimization is adopted in this paper. Moreover, for the height control system, the pressure of the chamber without piston is highly dependent on the mechanical structure parameters, i.e., inner diameter of hydraulic cylinder $D$, length of hydraulic cylinder barrel $L_{0}$ and the length of $\operatorname{rod} A C L_{2}$. The response time and displacement error is related to the combination of the mechanical structure parameters (i.e., inner diameter of hydraulic cylinder $D$, length of hydraulic cylinder barrel $L_{0}$ ) and control parameters. (i.e., proportion coefficient $K_{P}$, integration coefficient $K_{I}$ and differential coefficient $K_{D}$ ). Hence, during the optimization process, the mechanical structure parameters and control parameters are both taken as the optimization variables. With the obtained optimal mechanical structure parameters and control parameters, a better height control system can be designed to reduce the probability of the spindle cotton picker colliding to the ground. In this section, a multi-objective optimization model is proposed firstly. Then an algorithm combined OvS, PSO and SA is proposed to solve the model.

\subsection{Optimization Objectives and Variables}

\subsubsection{Pressure of the Chamber without Piston}

In a hydraulic system, the lower the pressure in the chamber without piston is, the lower the pressure required by the hydraulic system is. As a result, the reliability of the hydraulic system will be improved. Hence, in this paper, the pressure of the chamber without piston $P_{1}$ is set as an optimization objective.

Oil return circuit is directly connected to the oil tank from the hydraulic schematic diagram, so $P_{2}=0$. According to Eq.(7), $P_{1}$ is expressed as follows:

$$
P_{1}=\frac{4}{\pi D^{2}}\left[\frac{4 L_{1}^{2}\left(L_{2}+L_{4}\right)^{2}}{4 L_{2}^{2} L_{3}^{2}-\left(L_{2}^{2}+L_{3}^{2}-L_{1}^{2}\right)^{2}} \frac{G}{g} \frac{\mathrm{d}^{2} L}{\mathrm{~d} t^{2}}+B \frac{\mathrm{d} L}{\mathrm{~d} t}+\frac{G\left(L_{2}+L_{4}\right)\left(L_{0}+L\right)}{L_{2} L_{3}}\right]
$$

\subsubsection{Response time and displacement error}

For the height control system of the spindle cotton picker, response time to and displacement error $e$ are two vital performance indicators. With the aim to improve the profiling precision, reduce response time of hydraulic cylinder and decrease the probability of spindle colliding to the ground, the response time to and displacement error $e$ are chosen to be optimization objectives. For the sake of algorithmic convergence, the response time $t_{0}$ and displacement error $e$ are merged into one normalized objective $H$, which can be seen in Eq.(15). 


$$
H=\omega_{1} \frac{t_{0}}{t_{o p t}}+\omega_{2} \frac{e}{e_{o p t}}
$$

where $t_{\text {opt }}$ and $e_{\text {opt }}$ are the response time and displacement error required by the height control system, $\omega_{1}$ and $\omega_{2}$ are the corresponding weights.

The hydraulic system of the height control system is complex with nonlinear characteristics. Its response time to and displacement error $e$ are influenced by multiple factors such as the mechanical structure parameters and control parameters. During the optimization process, it is difficult to establish a precise mathematical model of the hydraulic system to acquire the response time and displacement error. Hence, a simulation model based on AMESim is proposed to acquire the response time and displacement error of the hydraulic system.

The AMESim is a kind of software serving for advanced modeling and simulation of engineering systems based on intuitive graphical interface. It is specialized in multi-disciplinary collaborative simulation especially for mechanics, electronics and hydraulics. As the height control system is a typical mechanical-electro-hydraulic system, several libraries are involved to build the whole model, like hydraulic component design library for the hydraulic pump, planner mechanical library for mechanical attachments and control library for control operations. Meanwhile, the required parameters such as the inner diameter of hydraulic cylinder $D$ and length of hydraulic cylinder barrel $L_{0}$ are input in the model. The simulation model of the height control system can be seen in Figure 6 .

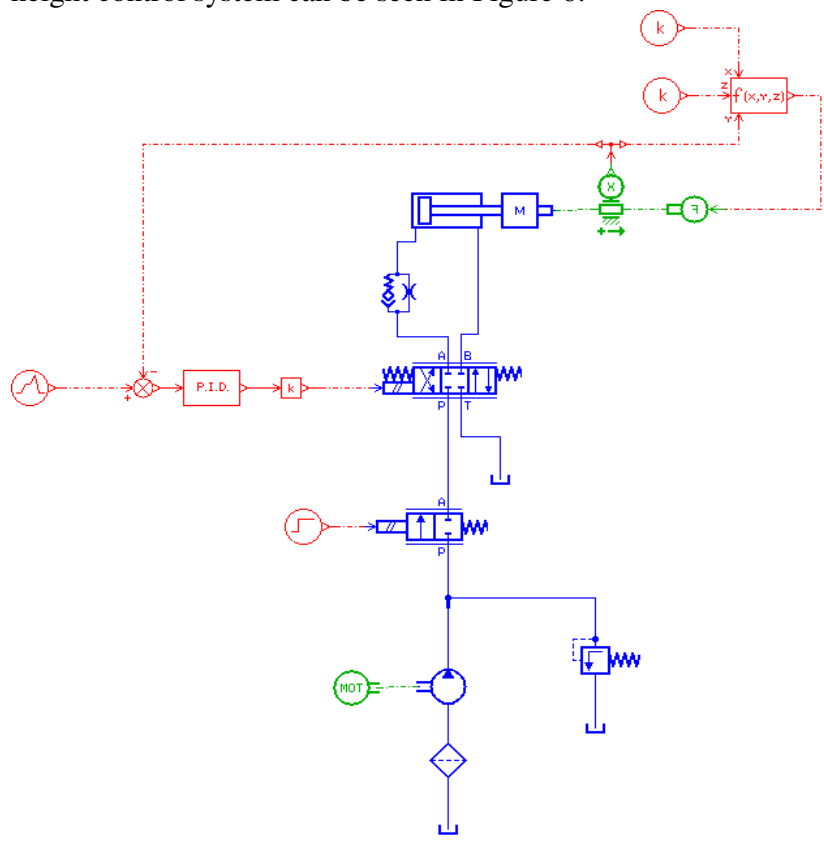

Figure 6 AMESim model of the height control system

\subsubsection{Variables}

The decision variables considered for the integrated optimization problem can be classified into two categories. One is related to the structure and the variables needed to be decided are the inner diameter of hydraulic cylinder $D$, length of hydraulic cylinder barrel $L_{0}$ and the length of $\operatorname{rod} A C L_{2}$. Another is the PID control parameters, i.e., proportion coefficient $K_{P}$, integration coefficient $K_{I}$ and differential coefficient $K_{D}$.

\subsection{Constraints}

(1) The inner diameter of hydraulic cylinder $D$ should be selected from the Standard GB/T2348, which can be seen in Eq.(16).

$$
D=[63,80,90,100,110,125,140,160,180]
$$

(2) The overall length of hydraulic cylinder $L_{1}$, length of rod $A C L_{2}$ and installation dimension $L_{3}$ are restricted to the geometry constraints of a triangle.

$$
\left\{\begin{array}{l}
L_{0}+L+L_{2}>L_{3} \\
L_{0}+L+L_{3}>L_{2} \\
L_{2}+L_{3}>L_{0}+L
\end{array}\right.
$$

where the overall length of hydraulic cylinder $L_{1}$ is the sum of the length of hydraulic cylinder barrel $L_{0}$ and travel range of piston $L$, installation dimension $L_{3}$ is constant.

The length of hydraulic cylinder barrel $L_{0}$ is:

$$
L_{0}=L_{\max }+B+L_{A}+L_{M}+L_{C}
$$

where $B$ is width of rod, $B=(0.6-0.8) D, L_{A}$ is the guiding distance of hydraulic rod, $L_{A}=(0.6-1.5) D, L_{M}$ is sealing distance of hydraulic rod determined by sealing method, $L_{C}$ is the rest length of hydraulic cylinder barrel.

(3) The length of hydraulic cylinder barrel $L_{0}$ is within twenty times the length of its inner diameter.

$$
L_{0}<20 D
$$

(4) The lifting height should be more than $100 \mathrm{~mm}$ when the hydraulic cylinder reaches its maximum travel range.

$$
\frac{L_{\max }^{2}+2 L_{0} L_{\max }}{2 L_{3}}>100
$$

where $L_{\max }$ is the maximum travel range of hydraulic cylinder.

(5) The PID parameters are restricted by the reasonable ones.

$$
\left\{\begin{array}{l}
0<K_{P}<K_{P \max } \\
0<K_{I}<K_{\text {Imax }} \\
0<K_{D}<K_{D \max }
\end{array}\right.
$$

where $K_{P \max }, K_{I \max }$ and $K_{D \max }$ are the maximum values of $K_{P}, K_{I}$ and $K_{D}$. The widely used method for acquiring these values is simulation tests. During each test, one of the PID parameters is changed while another two parameters are remain unchanged. If the response time and displacement error of the height control system are within a reasonable range, then the value of the changed parameter will be recorded. The tests will last for several times until all the maximum values of the three PID parameters are settled. 


\subsection{Optimization Model}

Based on the analysis above, a multi-objective optimization model with the aim to minimize the pressure of chamber without piston, response time and displacement error of the height control system, is then formulated as shown in Eq.(22).

$$
\begin{aligned}
& \min \left[P_{1}\left(L_{0}, D, L_{2}\right), H\left(L_{0}, D, K_{P}, K_{I}, K_{D}\right)\right] \\
& \text { s.t. }\left\{\begin{array}{l}
D=[63,80,90,100,110,125,140,160,180] \\
L_{0}+L+L_{2}>L_{3} \\
L_{0}+L+L_{3}>L_{2} \\
L_{2}+L_{3}>L_{0}+L \\
\frac{L_{\max }^{2}+2 L_{0} L_{\max }}{2 L_{3}}>100 \\
L_{0}<20 D \\
0<K_{P}<K_{P \max } \\
0<K_{I}<K_{I \max } \\
0<K_{D}<K_{D \max }
\end{array}\right.
\end{aligned}
$$

\subsection{Optimization Solution}

In this paper, the optimization model is solved via a simulation based optimization method. The response time and displacement error of the hydraulic cylinder are firstly acquired by the AMESim platform. Then the simulation results are chosen to be fitness functions of the multi-objective optimization model. For the discrete structure parameters, i.e., inner diameter of hydraulic cylinder $D$, length of hydraulic cylinder barrel $L_{0}$ and length of rod AC $L_{2}$, they are firstly searched using SA and the optimal control parameters $K_{P}, K_{I}$ and $K_{D}$ for each set of structure parameters are then obtained through PSO algorithm. The reason for choosing SA and PSO is that the SA is capable of high searching efficiency and fast convergence speed for solving discrete optimization problem [33] and so does the PSO for continuous optimization problems[34, 35]. The flowchart of the algorithm is shown in Figure 7 and the detailed procedure is described as follows.

Step 1: Set the parameters of SA and PSO. Generate initial solution $x \_$current $\left(D, L_{0}, L_{2}, K_{P}, K_{I}, K_{D}\right)$ and calculate objective function $\operatorname{object}\left(P_{1}, H\right)$. Set $x_{S A \_c u r r e n t}$ as $x \_$current $(1: 3)$.

Step 2: Enter the outer loop of SA. Judge whether the temporary temperature temp is greater than the minimum temperature temp $\min$ set in Step 1 or not. If so, go to Step 3. Otherwise, go to Step 10.

Step 3: Judge whether the current iteration count $g$ is less than the maximum iteration count $g^{M}$ or not. If so, go to Step4. Otherwise, go to Step 9.

Step 4: Randomly generate the adjacent solution $x_{S A}$ new of $x_{S A}$ c current in the outer loop of SA and calculate the pressure object $S_{\text {_ }}$ new $\left(P_{1}\right)$ of the chamber without piston in the hydraulic cylinder.

Step 5: Enter the inner loop of PSO and calculate the optimal PID parameters corresponding to the structural parameters $x_{S A \_n e w}$ generated in Step 4. The details are as follows.

(1) Initialize the PSO, generate the initial solution $x_{\text {pos_current }}\left(K_{P i}, K_{I i}, K_{D i}\right)$. Invoke the model in AMESim and get the output results of response time and displacement error of hydraulic cylinder, namely the value of objective function

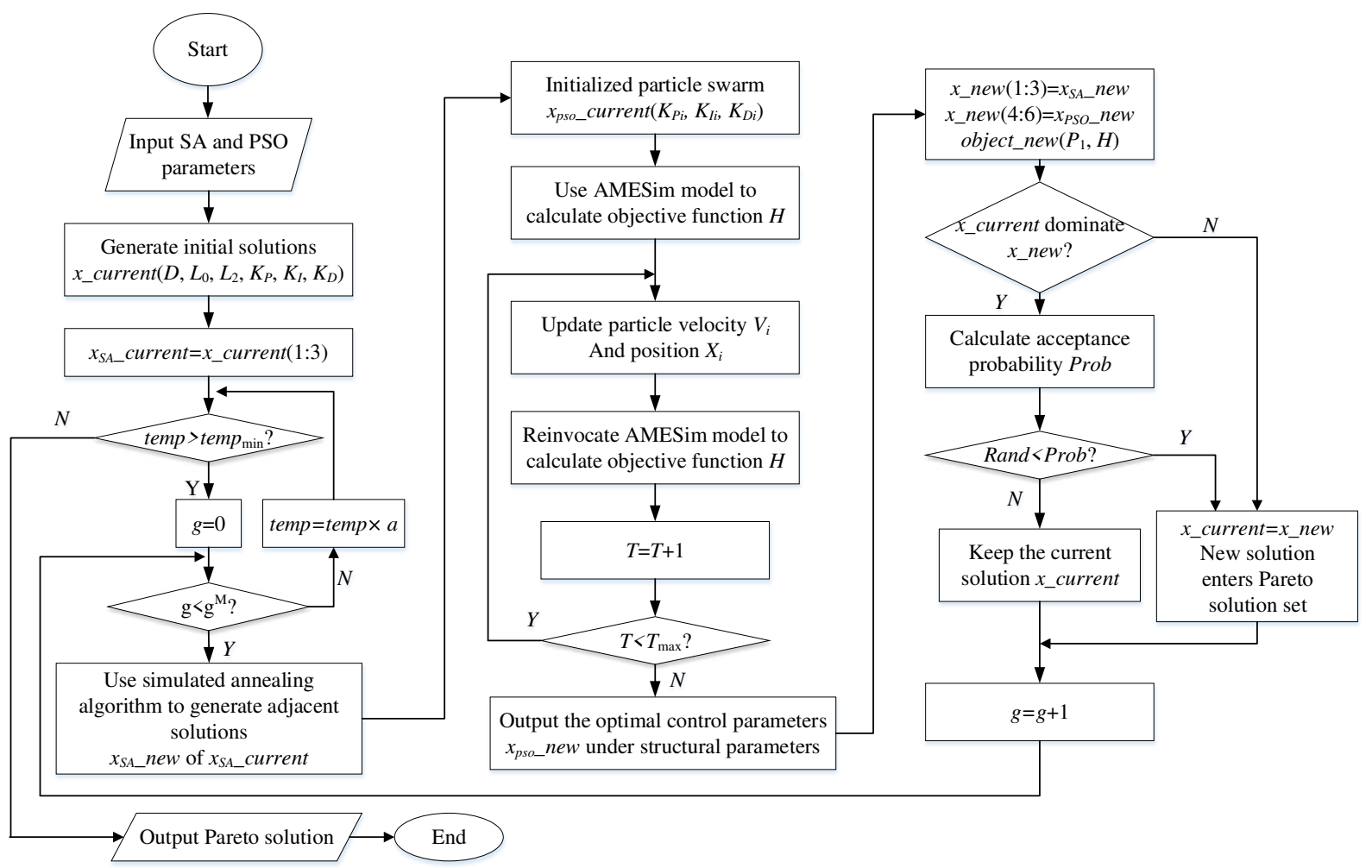

Figure 7 Simulation based optimization algorithm flow 
object pso_current $(H)$.

(2) Update the velocity $v_{i d}$ and position $x_{i d}$ of every particle according to (23) and (24) and generate the adjacent solution $x_{\text {pos_n }}$ new $\left(K_{P i}, K_{I i}, K_{D i}\right)$ of PSO. Invoke the model in AMESim and obtain the output results of response time and displacement error of profiling hydraulic cylinder, namely the value of objective function object pso_new $(H)$.

$$
\begin{gathered}
v_{i d}^{T+1}=\omega \times v_{i d}^{T}+c_{1} \times r_{1} \times\left(p_{i d}-x_{i d}^{T}\right)+c_{2} \times r_{2} \times\left(p_{g d}-x_{i d}^{T}\right) \\
x_{i d}^{T+1}=x_{i d}^{T}+v_{i d}^{T+1}
\end{gathered}
$$

where $v_{i d}^{T}$ and $x_{i d}^{T}$ are velocity and position of $d-t h(d=1,2$ or 3$)$ dimension of $i$-th particle in $T$-th iteration, $p_{i d}$ is the best position of each particle during the iterative process, $p_{g d}$ is the best position of all particles in the temporary iterative procedure, $c_{1}$ and $c_{2}$ are learning factors, $r_{1}$ and $r_{2}$ are two random numbers, $\omega$ is inertia weight.

(3) Update the iteration count of PSO, $T=T+1$.

(4) Judge whether the current iteration count $T$ is greater than the maximum iteration count $T_{\max }$ or not. If so, go back to step 5.2), otherwise go to step 5.5).

(5) Generate the optimal PID parameters $x_{\text {pos_new }}$ that are related to the structure parameters from the outer loop of SA. Step 6: Set $x \_n e w(1: 3)$ as $x$ SA_new, $x \_n e w(4: 6)$ as $x_{\text {pos_new }}$ and value of objective function object_new as $\left(P_{1}, H\right)$.

Step 7: Judge the dominating relationship of the solutions in SA. The details are as follows:

(1) Judge whether $x \_n e w$ is dominated by $x \_c u r r e n t$ or not. If not, set $x \_c u r r e n t$ as $x \_n e w$ and add $x \_n e w$ to Pareto Archive, otherwise, go to step7.2).

(2) Calculate the probability of acceptance Prob according to Eq.(25).

$$
\text { Prob }=\exp \left(\frac{-\Delta E}{\text { temp }}\right)
$$

where $\Delta E=E\left(f\left(x \_n e w\right), \lambda\right)-E\left(f\left(x \_\right.\right.$current $\left.), \lambda\right), E(f(x), \lambda)=\lambda_{1} P_{1}+$ $\lambda_{2} H$. $\lambda_{1}$ and $\lambda_{2}$ are set as 0.5 .

(3) Generate a random number Rand and judge whether Rand is less than Prob or not. If so, set $x \_$current as $x \_n e w$ and add $x \_n e w$ to the Pareto Archive. Otherwise, retain $x \_$current.

Step 8: Update the iteration count of SA, $g=g+1$. Go back to Step 3.

Step 9: A commonly-used exponent cooling strategy is adopted in the outer loop of SA:

$$
\text { temp }=a \times \text { temp }
$$

where $a$ is the cooling factor of SA and faster cooling speed is achieved with less value of $a$. Go back to Step2.

Step 10: Output the Pareto Archive.

\section{Case study}

To validate the proposed multi-objective optimization model and algorithm and gain a better understanding of the influence of structure parameters and control parameters on pressure of the chamber without piston, response time and displacement error, a series of experiments are carried out in this section.

\subsection{Optimization Results}

To verify the effectiveness of the proposed approach, three optimization cases are studied. Hydraulic parameters and structure parameters of the height control system for the cotton picker are shown in Table 1. Parameters of SA and PSO are given in Table 2. Optimization results are shown in Table 3.

Case 1: Height control system with original structure parameters and PID control parameters.

Case 2: Height control system with optimal PID control parameters but original structure parameters.

Case 3: Height control system with optimal structure parameters and PID control parameters obtained by the proposed integration optimization approach.

Table 1 Hydraulic parameters and structure parameters of height control system

\begin{tabular}{lcc} 
Parameter & Value & Unit \\
\hline Engine rated speed & 2200 & $\mathrm{r} / \mathrm{min}$ \\
Rated displacement of pump & 90 & $\mathrm{~mL} / \mathrm{min}$ \\
Rated pressure of pump & 40 & $\mathrm{MPa}$ \\
Speed of pump & 2000 & $\mathrm{r} / \mathrm{min}$ \\
Rated current of servo valve & 200 & $\mathrm{~mA}$ \\
Rated flow of servo valve & 75 & $\mathrm{~mL} / \mathrm{min}$ \\
Natural frequency & 50 & $\mathrm{~Hz}$ \\
Damping ratio & 1 & \\
Servo amplifier gain & 250 & \\
Overflow pressure of overflow valve & 16 & $\mathrm{MPa}$ \\
G & 20000 & $\mathrm{~N}$ \\
$L_{2}$ & 850 & $\mathrm{~mm}$ \\
$L_{3}$ & 750 & $\mathrm{~mm}$ \\
$L_{4}$ & 1000 & $\mathrm{~mm}$ \\
\hline
\end{tabular}

Table 2 Algorithm parameters of height control system

\begin{tabular}{lcc}
\multicolumn{1}{c}{ Parameter } & Symbol & Value \\
\hline Initial temperature of SA & temp & 200 \\
Minimum temperature of SA & temp $_{\text {min }}$ & 10 \\
Maximum iterations of SA & $g^{M}$ & 100 \\
Cooling factor of SA & $a$ & 0.98 \\
Learning factor of PSO & $c_{1}$ & 2 \\
Learning factor of PSO & $c_{2}$ & 2 \\
Inertia weight of PSO & $\omega$ & 0.2 \\
Population size of the particles & $N$ & 40 \\
Maximum iterations of PSO & $T$ & 500
\end{tabular}


Table 3 Optimization results

\begin{tabular}{lccc}
\hline Parameters & Case 1 & Case 2 & Case 3 \\
\hline$L_{0}$ & 900 & 900 & 1006 \\
$L_{2}$ & 850 & 850 & 613 \\
$D$ & 100 & 100 & 110 \\
$K_{P}$ & 18 & 14 & 10.33 \\
$K_{I}$ & 0.25 & 0.52 & 0.57 \\
$K_{D}$ & 0.1 & 0.02 & 0.01 \\
\hline
\end{tabular}

\subsubsection{Simulation results under an identical height}

According to the structural parameters of the height control system and displacement of the hydraulic cylinder, the pressure of the chamber without piston $P_{1}$ for the three cases is calculated and plotted in Figure 8.

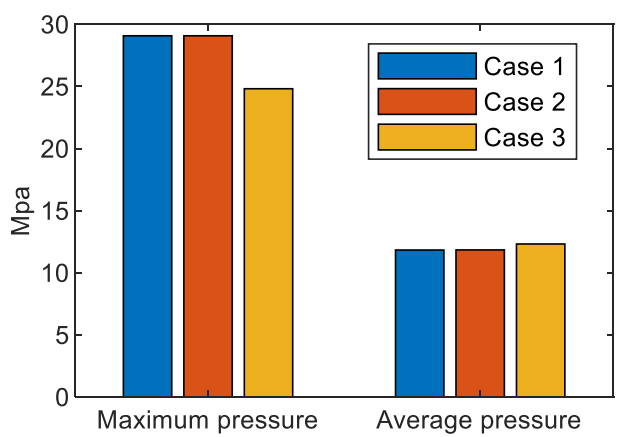

Figure 8 Pressure of hydraulic cylinder for different cases

From Figure 8 , it can be seen that the maximum pressure of Case 1, Case 2 and Case 3 is 29.07 MPa, 29.07 MPa and 24.81 $\mathrm{MPa}$, respectively. Compared with Case 1 and Case 2, the maximum pressure of Case 3 is reduced by $14.65 \%$. Furthermore, it also can be found that the average pressure of Case 1, Case 2 and Case 3 is $11.82 \mathrm{MPa}, 11.82 \mathrm{MPa}$ and $12.31 \mathrm{MPa}$, respectively. The average pressure is slightly increased by $4.15 \%$ when compared with Case 1 and Case 2. Note that the maximum pressure and average pressure of Case 1 and Case 2 are the same. This is because the load of the hydraulic cylinder will not be changed if only control parameters are optimized but structural parameters remains unchanged.

To study the response characteristics of the three cases under the same height, an AMESim simulation is performed. During the simulation process, the output load of the hydraulic cylinder is set to be the maximum load. As the step signal is the most common and useful reference signal for judging the response characteristics of a controlled system, during the simulation, the step signal is used to study the response characteristics of the height control system. The lifting height of spindle cotton picker is set to be $100 \mathrm{~mm}$. The displacement of the hydraulic cylinder for the three cases is calculated by Eq.(8) and the piston displacement of Case 1, Case 2 and Case 3 is $80 \mathrm{~mm}, 80 \mathrm{~mm}$ and $72 \mathrm{~mm}$. Simulation is carried out with step signal as shown in Figure 9.

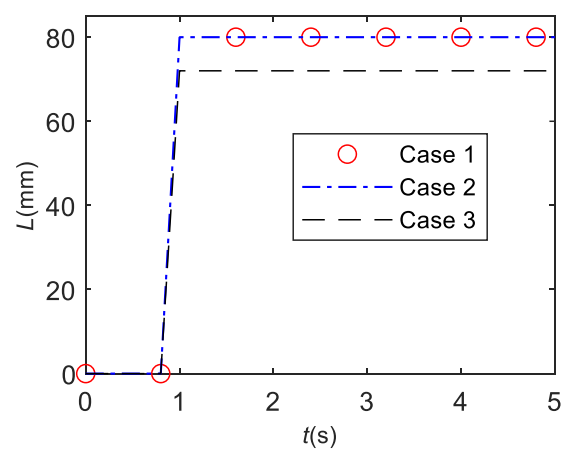

Figure 9 Displacement of the hydraulic cylinder before and after optimization

In Figure 10, the response curves of Case 1, Case 2 and Case 3 is given. The response time of the three cases are $0.98 \mathrm{~s}, 0.75 \mathrm{~s}$ and $0.48 \mathrm{~s}$ respectively. Moreover, the displacement error of the three cases is $4.0 \%, 2.6 \%$ and $1.1 \%$. The response time and displacement error of Case 3 are less than that of Case 1 or Case 2. This is because the displacement of the piston $\operatorname{rod} L$ for Case 3 is smaller than that of Case 1 and Case 2 under the same required height. Moreover, from Figure 10, it can be found that the control parameters has a great influence on the response time and displacement error of the height control system.

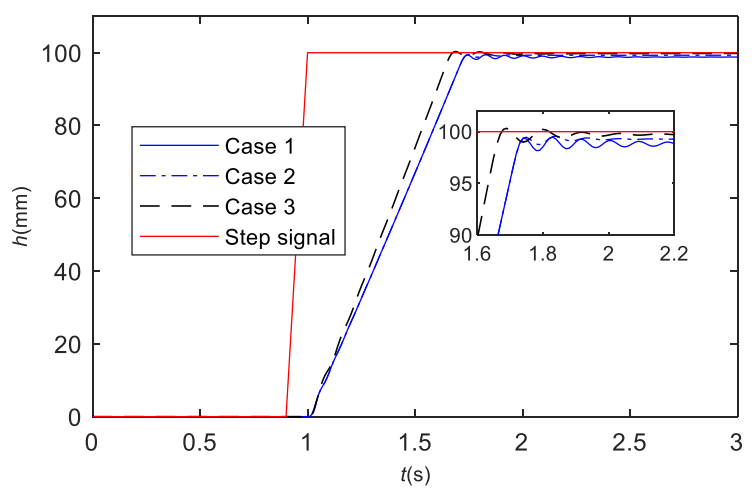

Figure 10 Comparison of response curves under the same height

\subsubsection{Simulation results under an identical displacement}

In order to verify the performance of the height control system, comparative simulations are made on the three cases with the same displacement of $80 \mathrm{~mm}$. From Figure 11, it can be seen that the maximum pressure of the chamber without piston for Case 1 and Case 2 is $29.07 \mathrm{MPa}$, while the maximum pressure of Case 3 is only $24.81 \mathrm{MPa}$. Compared to Case 1 and Case 2, the maximum pressure of Case 3 is reduced by $14.65 \%$. From Figure 12 , it can be found that the response time of Case 3 is $0.62 \mathrm{~s}$, which is reduced by $18.42 \%$ compared with Case 1 and Case 2 . Besides, the displacement error of Case 3 is reduced by $1.4 \%$. It can be found that significant improvement is achieved with the proposed optimization approach. 
From the analysis above, it can be found that the optimal control parameters will vary with different structure parameters, optimization of structure parameters and control parameters in an integrated manner can further reduce the pressure, shorten the response time, and improve the positioning accuracy of the height control system.

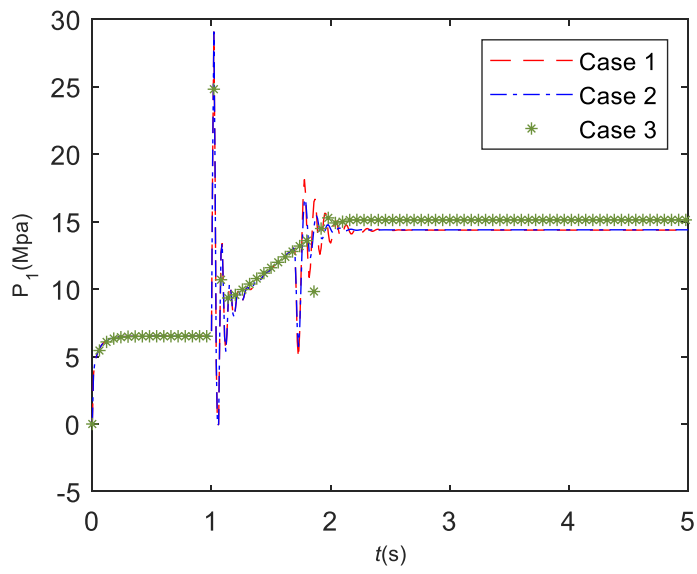

Figure 11 Pressure comparison of the three cases

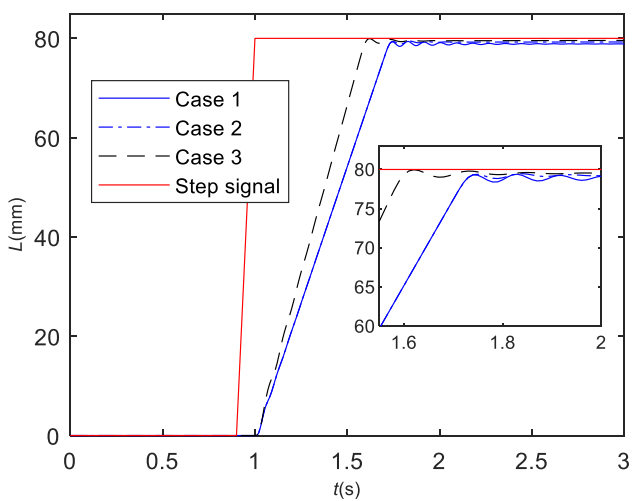

Figure 12 Comparison of displacement response

\subsection{Experimental Validation}

According to the optimal structure and PID control parameters shown in Table 3, as shown in Figure 13, a height control system for a cotton picker is constructed. In order to verify its performance, a practical test is carried out. Obstacles with the height of $100 \mathrm{~mm}, 80 \mathrm{~mm}$ and $50 \mathrm{~mm}$ are put on a smooth road to simulate the fluctuation of cotton field ground. The cotton picker travels through obstacles at a working speed of $5.8 \mathrm{~km} / \mathrm{h}$. The response time of the height control system is recorded as shown in Table 4. From Table 4, it can be found that the response time is $0.55 \mathrm{~s}, 0.43 \mathrm{~s}$ and $0.28 \mathrm{~s}$ under the height of $100 \mathrm{~mm}, 80 \mathrm{~mm}$ and $50 \mathrm{~mm}$. All the response time is less than $0.93 \mathrm{~s}$, which is the maximum response time to lift the picking unit to avoid colliding the obstacles at a speed of $5.8 \mathrm{~km} / \mathrm{h}$. This proves that the optimal structure and control parameters of the height control system can meet the practical requirements.

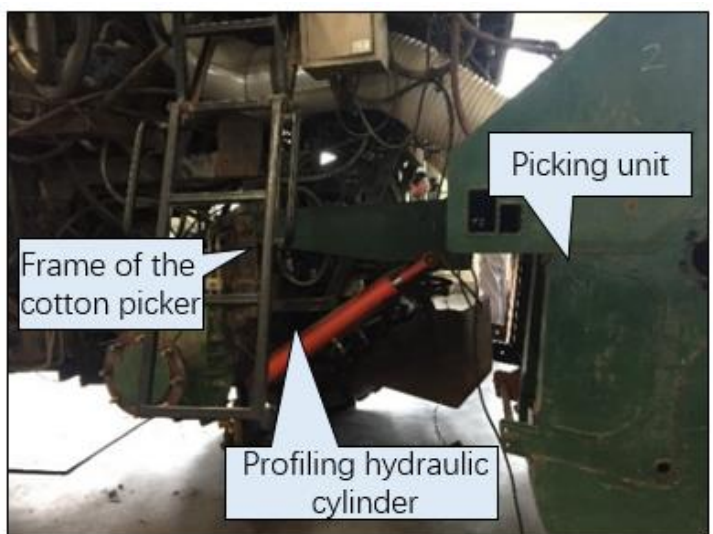

Figure 13 The height control system of spindle cotton picker

Table 4 Response time of the height control system

\begin{tabular}{lcc}
\hline Height $h(\mathrm{~mm})$ & Piston displacement $L(\mathrm{~mm})$ & Response time $t(s)$ \\
\hline 100 & 72 & 0.55 \\
80 & 58 & 0.43 \\
50 & 36 & 0.28 \\
\hline
\end{tabular}

\section{Conclusions}

In this paper, a vertical spindle cotton picker has been presented to solve existing problems in the traditional spindle cotton picker. A mechanical-electric-hydraulic coupled height control system is designed for the vertical cotton picker to avoid collision between spindles and bumps, and improve the efficiency of cotton picking. Both structure and control parameters are optimized to improve terrain-tracking performance of the height control system. A multi-objective integrated optimization model is established, which takes the pressure, response time and displacement error as the optimization objectives. The multi-objective integrated optimization model is solved by using the optimization method based on AMESim simulation. The advantage of proposed multi-objective integrated optimization approach is demonstrated by simulation and practical experiments. Results show that the maximum pressure of the hydraulic cylinder, the response time and the displacement error can be effectively reduced with the proposed integrated optimization approach.

Future work will be focused on the following aspects. Effects of the SA and PSO algorithm parameters on the optimization results of the height control system are not analyzed in the current study. It is expected that these works will be the future work. More improved optimization algorithms such as Artificial Bee Colony and Cuckoo Search algorithm [36-38] will be proposed to solve the proposed multi-objective optimization model. 


\section{Declaration}

\section{Funding}

Supported by National Natural Science Foundation of China (51905448), Chongqing Technology Innovation and Application Program (cstc2018jszX-cyzdX0183) and the Fundamental Research Funds for the Central Universities of China (SWU119060).

\section{Availability of data and materials}

The datasets supporting the conclusions of this article are included within the article.

\section{Authors' contributions}

$\mathrm{XC}$ was in charge of the trial and wrote the manuscript. CL provided fundamental ideas and all support conditions of this paper. $\mathrm{RH}$ and NL conducted proof reading and made some critical revisions. $\mathrm{CZ}$ assisted the trial and simulations. All authors read and approved the final manuscript.

\section{Competing interests}

The authors declare no competing financial interests.

\section{Consent for publication}

Not applicable

\section{Ethics approval and consent to participate}

Not applicable

\section{References}

[1] H Kazemi, M Shokrgozar, B Kamkar, et al. Analysis of cotton production by energy indicators in two different climatic regions. Journal of Cleaner Production, 2018, 190: 729-736.

[2] J D Wanjura, R K Boman, M S Kelley, et al. Evaluation of commercial cotton harvesting systems in the southern high plains. Applied Engineering in Agriculture, 2013, 29(3): 321-332.

[3] G M Sharipov, D S Paraforos, H W Griepentrog. Modelling and simulation of the dynamic performance of a no-till seeding assembly with a semi-active damper. Computers and Electronics in Agriculture, 2017, 139: 187-197.

[4] G M Sharipov, D S Paraforos, A S Pulatov. Dynamic performance of a no-till seeding assembly. Biosystems Engineering, 2017, 158: 64-75.

[5] X Jin, K Zhao, J Ji, et al. Design and implementation of intelligent transplanting system based on photoelectric sensor and PLC. Future Generation Computer Systems, 2018, 88: 127-139.

[6] S K Nielsen, L J Munkholm, M Lamandé, et al. Seed drill depth control system for precision seeding. Computers and Electronics in Agriculture, 2018, 144: 174-180.

[7] H M Hanna, B L Steward, L Aldinger. Soil loading effects of planter depth-gauge wheels on early corn growth. Applied Engineering in Agriculture, 2008, 26(4): 551-556.
[8] R Zhang, T Cui, D Han. Design of depth-control planting unit with single-side gauge wheel for no-till maize precision planter. International Journal of Biometeorology, 2016, 9(6): 56-64.

[9] G M Sharipov, D S Paraforos, H W Griepentrog. Implementation of a magnetorheological damper on a no-till seeding assembly for optimising seeding depth. Computers and Electronics in Agriculture. 2018, 150: 465- 475

[10] P Suomi, T Oksanen. Automatic working depth control for seed drill using ISO 11783 remote control messages. Computers and Electronics in Agriculture, 2015, 116: 30-35.

[11] Y Zhu, Y Wang, X Zhen, et al. The control of an opposed hydraulic free piston engine. Applied Energy, 2014, 126: 213-220.

[12] J Yu, J Liu, Z Wu, et al. Depth control of a bioinspired robotic dolphin based on sliding mode fuzzy control method. IEEE Transactions Industrial Electronics, 2018, 65(3): 2429-2438.

[13] Z Sun, T W Kuo. Transient control of electro-hydraulic fully flexible engine valve actuation system. IEEE Transactions on Control Systems Technology, 2010, 18(3): 613-621.

[14] M Zhang, P Borja, R Ortega, et al. PID passivity-based control of port-hamiltonian systems. IEEE Transactions on Automatic Control, 2018, 63(4): 1032-1044.

[15] ŞÇetin, A V Akkaya. Simulation and hybrid fuzzy-PID control for positioning of a hydraulic system. Nonlinear Dynamics, 2010, 61: 465-476.

[16] B B Ghosh, B K Sarkar, R. Saha. Realtime performance analysis of different combinations of fuzzy-PID and bias controllers for a two degree of freedom electrohydraulic parallel manipulator. Robotics and Computer Integrated Manufacturing, 2015, 34: 62-69.

[17] R E Precup, R C David, E M Petriu. Grey wolf optimizer algorithm-based tuning of fuzzy control systems with reduced parametric sensitivity. IEEE Transactions on Industrial Electronics, 2016, 64(1): 527-534.

[18] R K Sahu, S Panda, G T C Sekhar. A novel hybrid PSO-PS optimized fuzzy PI controller for AGC in multi area interconnected power systems. International Journal of Electrical Power \& Energy Systems, 2015, 64: 880-893.

[19] Y Ye, C Yin, Y Gong, et al. Position control of nonlinear hydraulic system using an improved PSO based PID controller. Mechanical Systems \& Signal Processing, 2017, 83: 241-259.

[20] Z Cheng, Z Lu. Research on the PID control of the ESP system of tractor based on improved AFSA and improved SA. Computers and Electronics in Agriculture, 2018, 148: 142-147.

[21] M G Villarreal-Cervantes, C A Cruz-Villar, J Alvarez-Gallegos, et al. Robust structure-control design approach for mechatronic systems. IEEE/ASME Transactions on Mechatronics, 2013, 18(5): 1592-1601.

[22] M G Villarreal-Cervantes. Approximate and widespread Pareto solutions in the structure-control design of mechatronic systems. Journal of Optimization Theory and Applications, 2017, 173: 628-657.

[23] Y Zhang, D Yang, S Li. An integrated control and structural design approach for mesh reflector deployable space antennas. Mechatronics, 2016, 35: 71-81.

[24] L Chang, Z Zhou, Y Chen, et al. Belief rule base structure and parameter joint optimization under disjunctive assumption for nonlinear complex system modeling. IEEE Transactions on Systems, Man, and Cybernetics: Systems, 2018, 48(9): 1542-1554.

[25] X Niu, K Liu, Y Zhang, et al. Multiobjective optimization of multistage synchronous induction coilgun based on NSGA-II. IEEE Transactions on Plasma Science, 2017, 45(7): 1622-1628. 
[26] M M Silva, O Brüls, W Desmet, et al. Integrated structure and control design for mechatronic systems with configuration-dependent dynamics. Mechatronics, 2009, 19: 1016-1025.

[27] Z Feng, Q Zhang, Q Tang, et al. Control-structure integrated multiobjective design for flexible spacecraft using MOEA/D. Structural and Multidisciplinary Optimization, 2014, 50: 347-362.

[28] O Arrieta, R Vilanova, J D Rojas, et al. Improved PID controller tuning rules for performance degradation/robustness increase trade-off. Electrical Engineering, 2016, 98: 233-243.

[29] X Liu. Optimization design on fractional order PID controller based on adaptive particle swarm optimization algorithm. Nonlinear Dynamics, 2016, 84: 379-386.

[30] M V Javier, P A Ricardo, G M Manuel et al. Nonlinear PID-type controller for quadrotor trajectory tracking. IEEE/ASME Transactions on Mechatronics, 2018, 23(5): 2436-2447.

[31] M Van. An enhanced robust fault tolerant control based on an adaptive fuzzy PID-nonsingular fast terminal sliding mode control for uncertain nonlinear systems. IEEE/ASME Transactions on Mechatronics, 2018, 23(3): 1362-1371.

[32] H Feng, C Yin, W Weng, et al. Robotic excavator trajectory control using an improved GA based PID controller. Mechanical Systems \& Signal Processing, 2018, 105: 153-168.

[33] S J Ho, L Shu, S Ho. Optimizing fuzzy neural networks, for tuning PID controllers using an orthogonal simulated annealing algorithm OSA. IEEE Transactions on Fuzzy Systems, 2006, 14(3): 421-434.

[34] W Wu, L Gao. Parameter Optimization of a stability-training platform's 4-PSS/PS parallel mechanism based on training ability evaluation index and PSO algorithm. Chinese Journal of Mechanical Engineering, 2018, 31(1): 50.

[35] P Wang, X Chen, Y Zhang, et al. IBPSO-based MUSIC algorithm for broken rotor bars fault detection of induction motors. Chinese Journal of Mechanical Engineering, 2018, 31(1): 80.

[36] G Tian, M Zhou, P. Li. Disassembly sequence planning considering fuzzy component quality and varying operational cost. IEEE Transactions on Automation Science and Engineering, 2018, 15: 748-760.

[37] X Chen, C Li, Y Tang, et al. Integrated optimization of cutting tool and cutting parameters in face milling for minimizing energy footprint and production time. Energy, 2019, 175: 1021-1037.
[38] G Tian, Y Ren, Y Feng, et al. Modeling and planning for dual-objective selective disassembly using AND/OR graph and discrete artificial bee colony. IEEE Transactions on Industrial Informatics, 2019, 15: 2456-2468.

\section{Biographical notes}

Xing-Zheng Chen, born in 1990, is currently a Lecturer at College of Engineering and Technology, Southwest University. He received his Ph.D degree from Chongqing University, China, in 2018. His research interests include on electronic-hydraulic system optimization and energy efficient machining.

E-mail: chenxzh@swu.edu.cn

Cong Bo-Li, born in 1981, is currently a Professor at State Key Laboratory of Mechanical Transmission, Chongqing University, China. His main research interests include modeling and optimization control, green manufacturing, energy efficient manufacturing and remanufacturing.

E-mail: congboli@cqu.edu.cn

Rui-Hu, born in 1994, is currently a master candidate at State Key Laboratory of Mechanical Transmission, Chongqing University, China.

E-mail: hbhr0618@cqu.edu.cn

Ning-Liu, born in 1989, is currently a Research Fellow at Department of Mechanical Engineering, National University of Singapore, Singapore. His research interests include artificial intelligence for industrial solutions, metallic additive manufacturing and industrial automation.

E-mail: liuning@u.nus.edu

Chi-Zhang, born in 1995, is currently a master candidate at State Key Laboratory of Mechanical Transmission, Chongqing University, China.

E-mail: 13678418764@163.com 


\section{Figures}
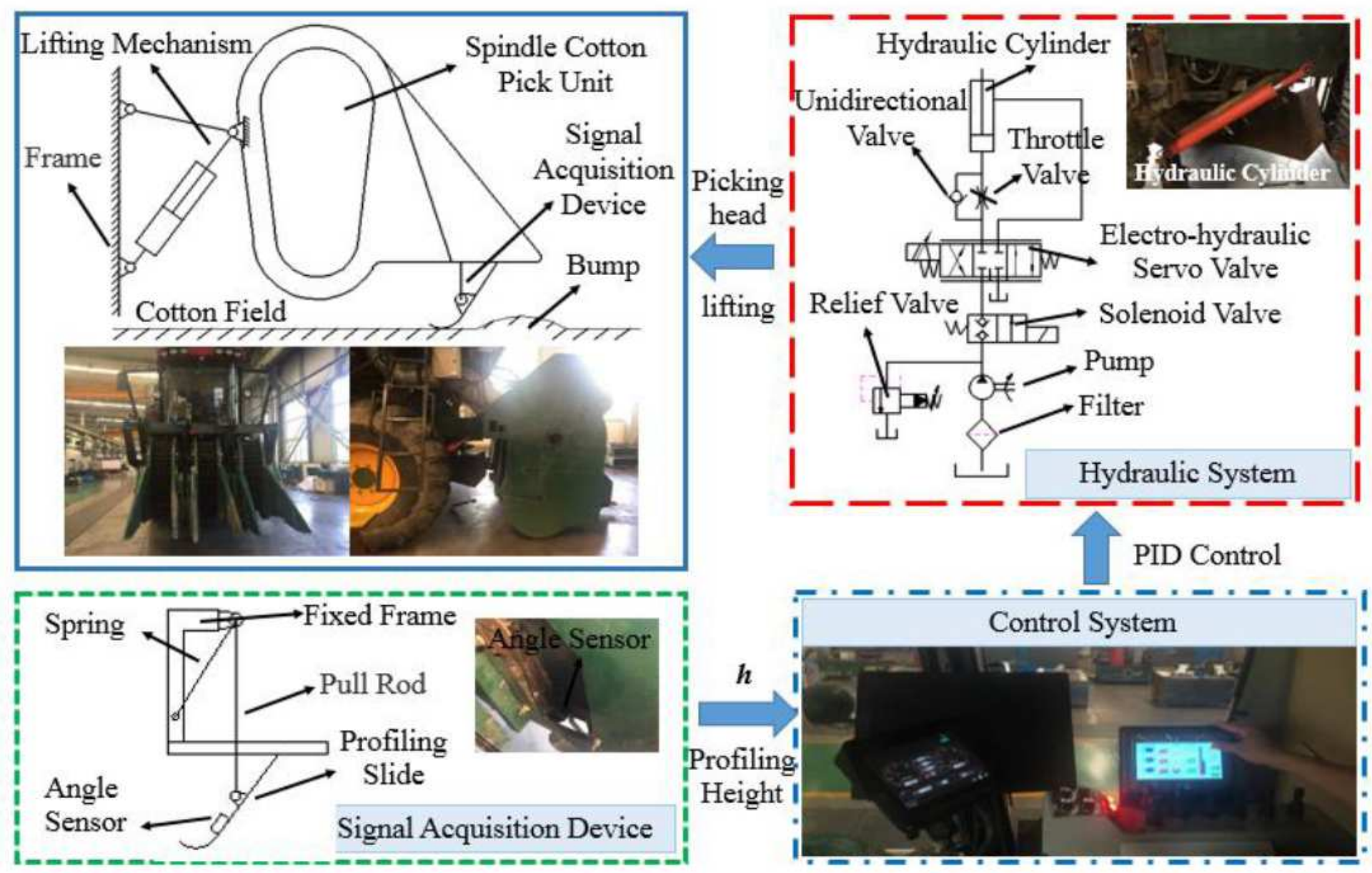

Figure 1

Schematic graph of the height control system 


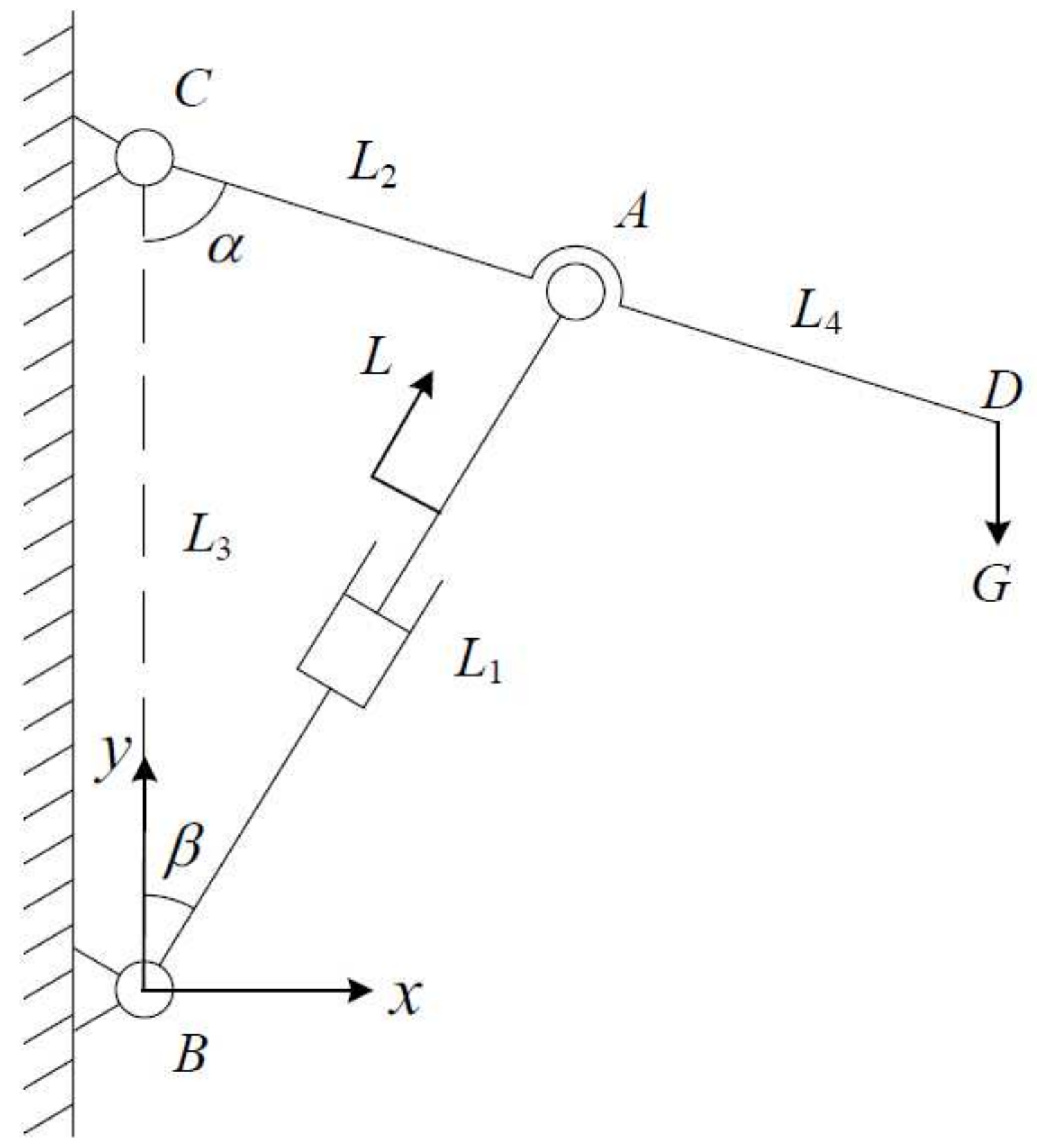

Figure 2

Schematic diagram of the lifting mechanism 


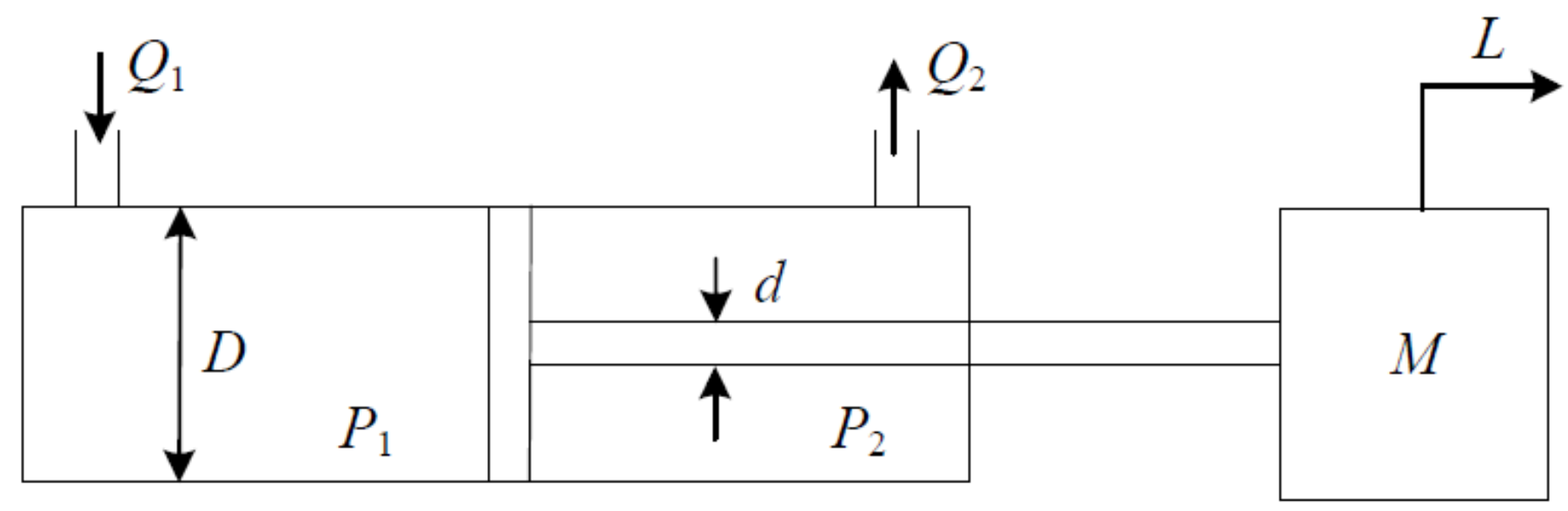

Figure 3

Equivalent model of the lifting mechanism 


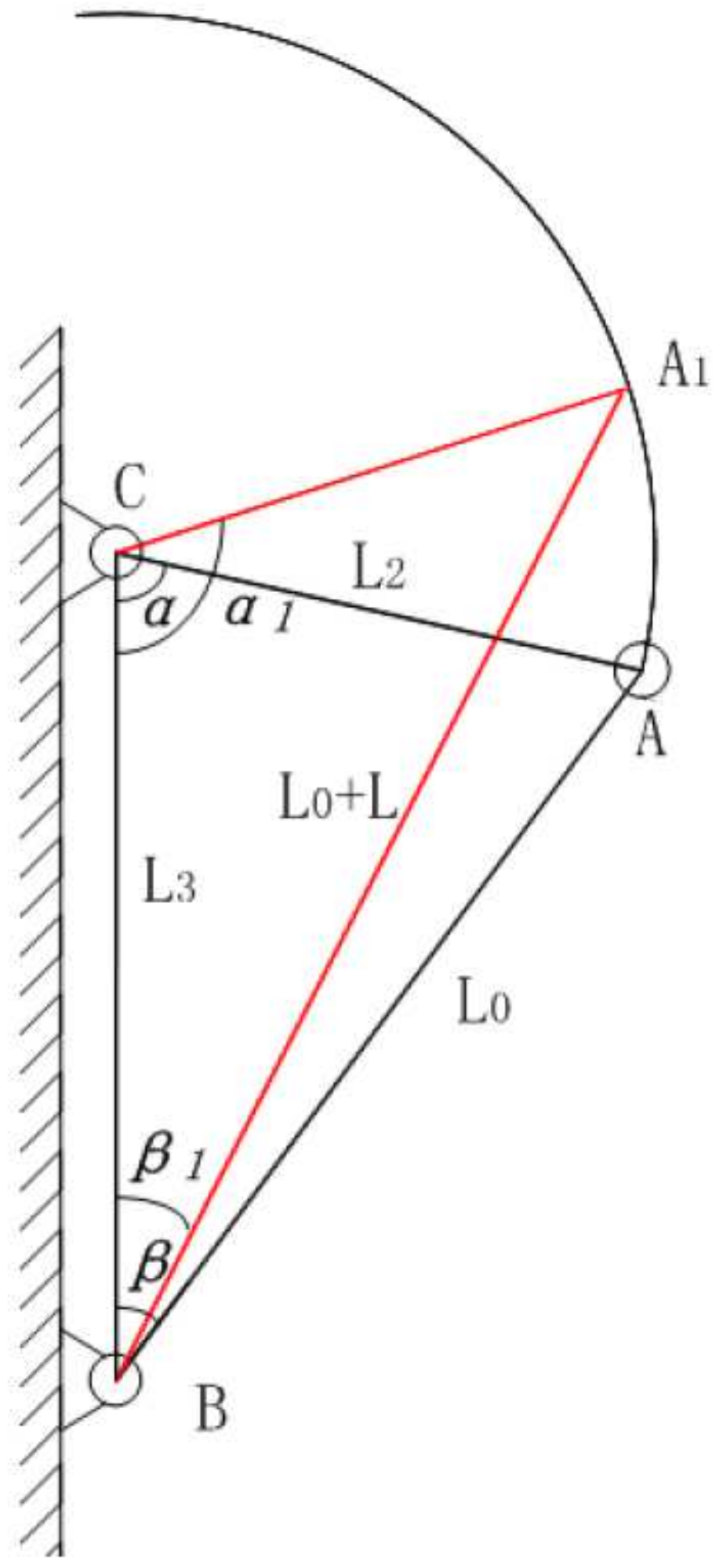

Figure 4

Kinematic analysis of lifting mechanism 


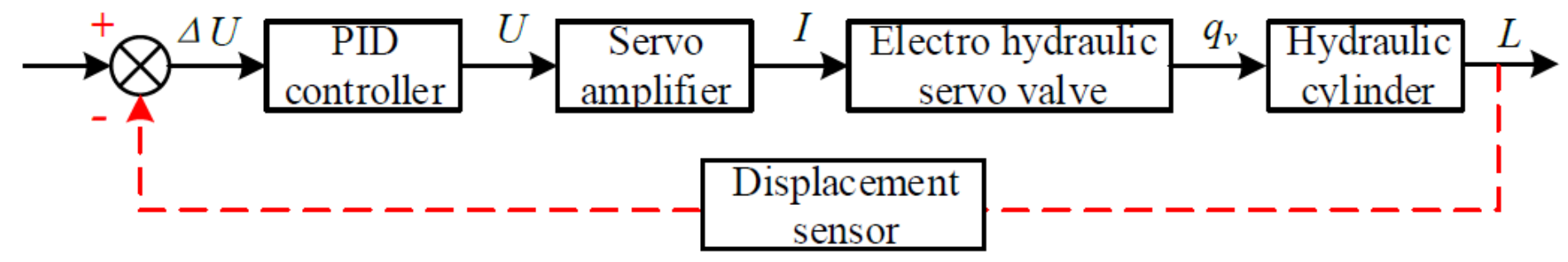

Figure 5

Control block diagram of hydraulic system

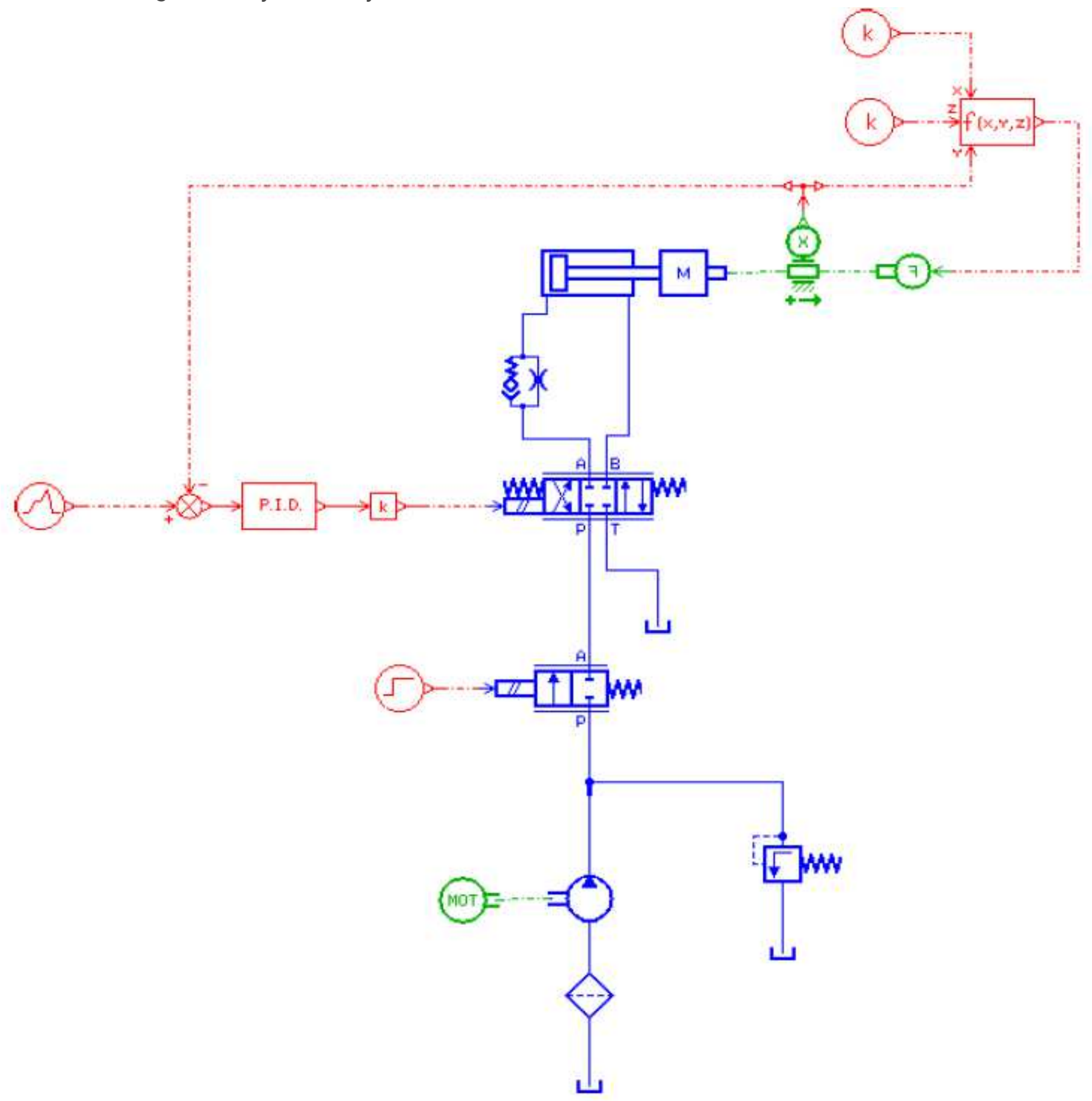




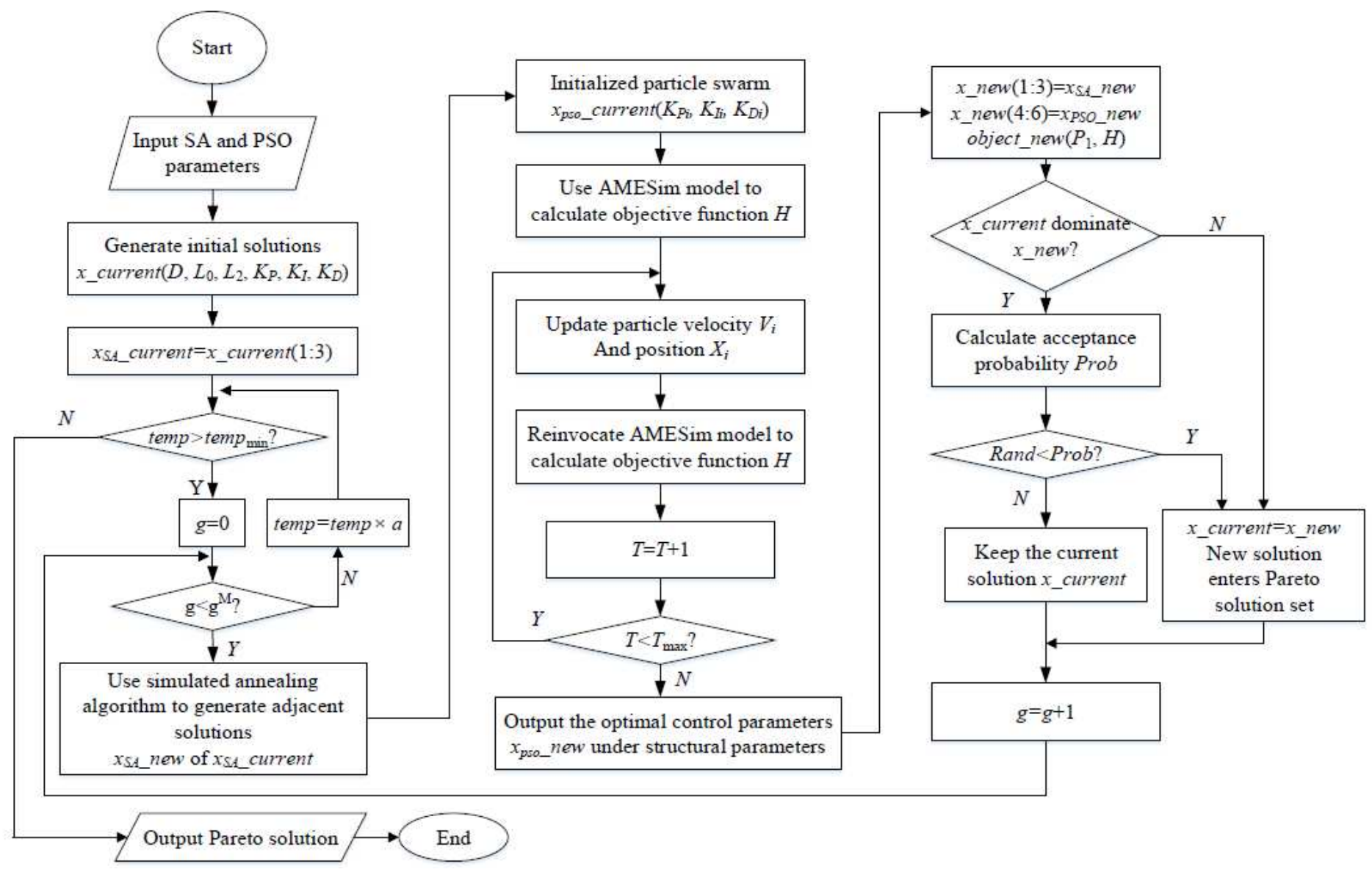

Figure 7

Simulation based optimization algorithm flow 


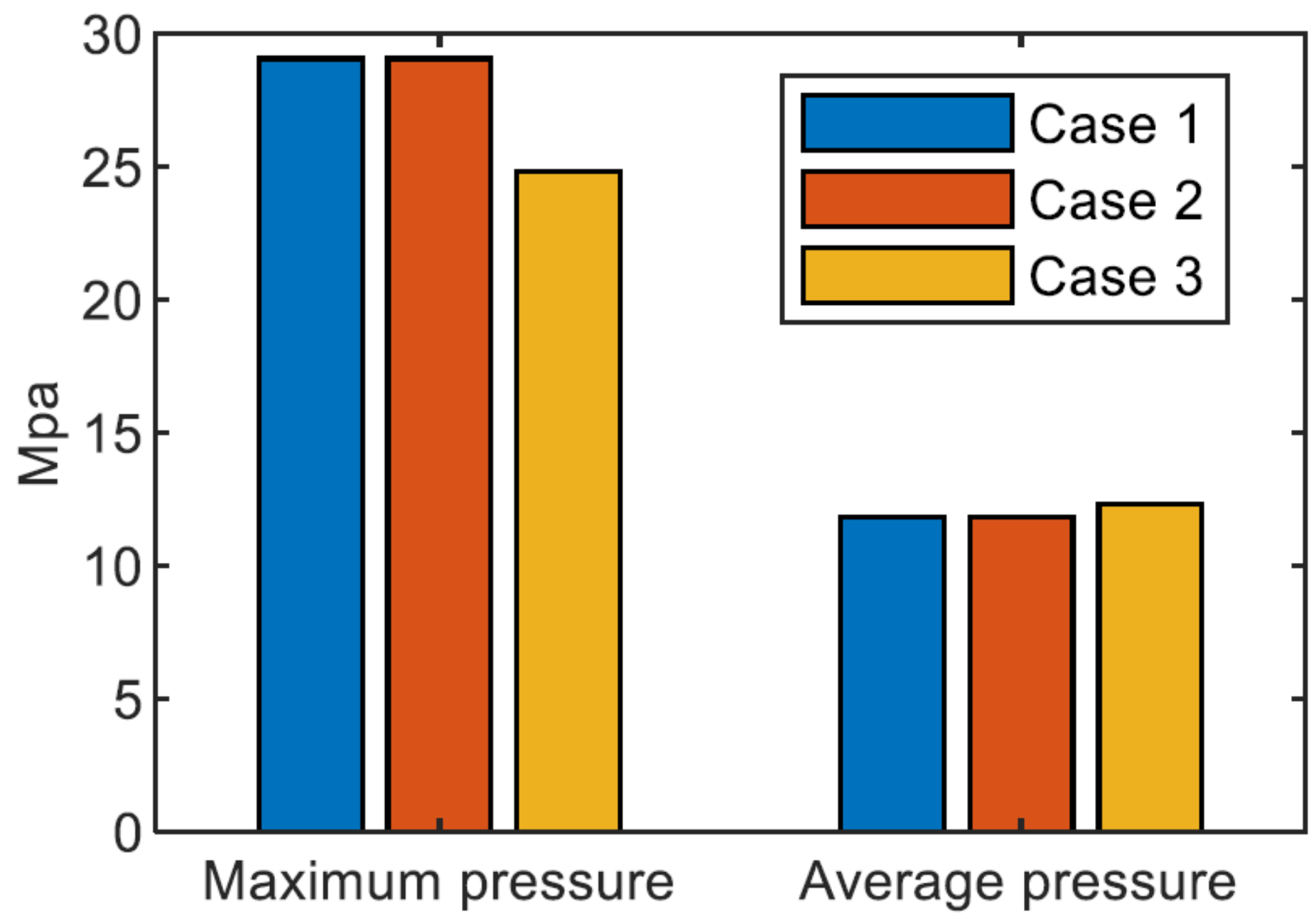

Figure 8

Pressure of hydraulic cylinder for different cases 


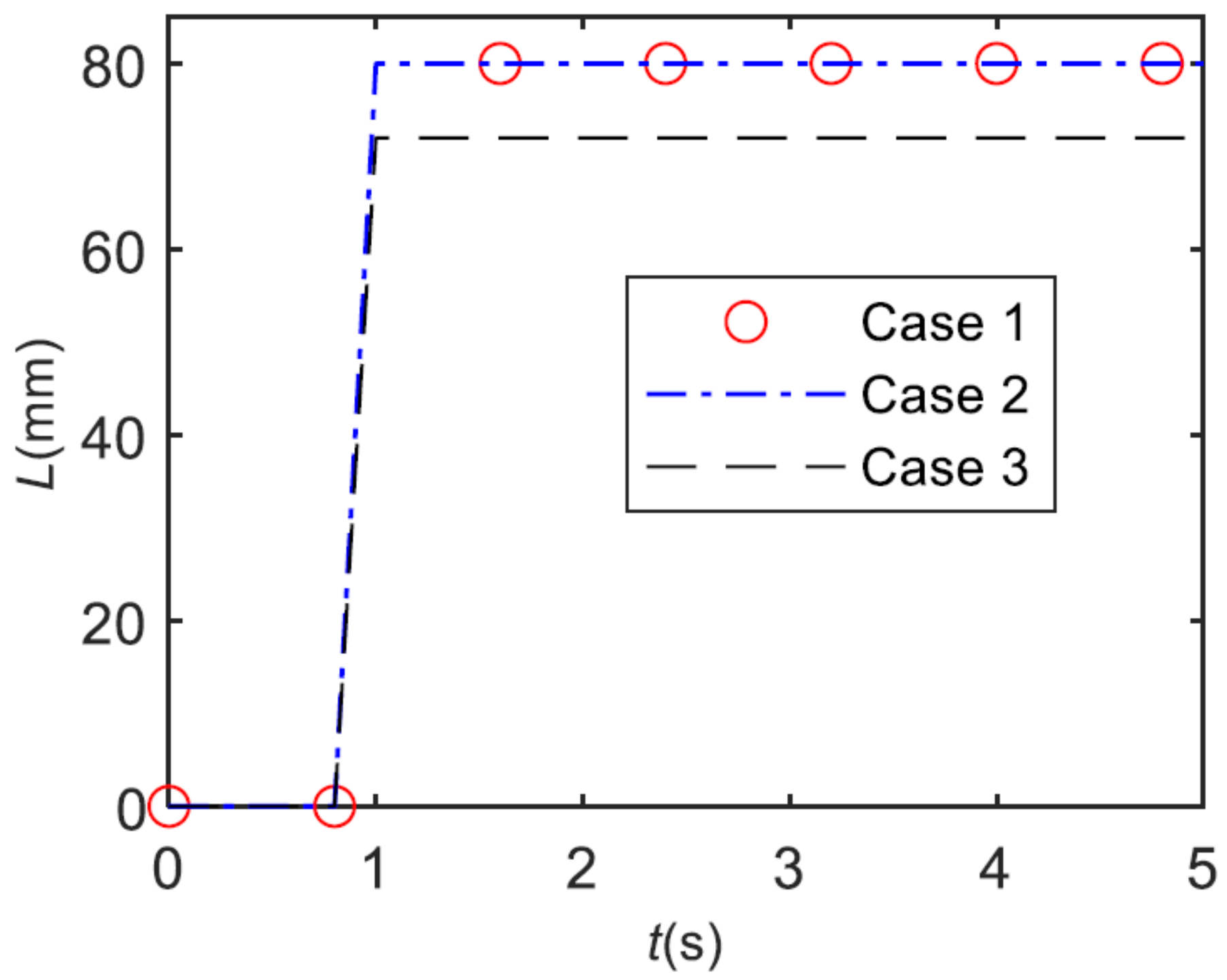

Figure 9

Displacement of the hydraulic cylinder before and after optimization 


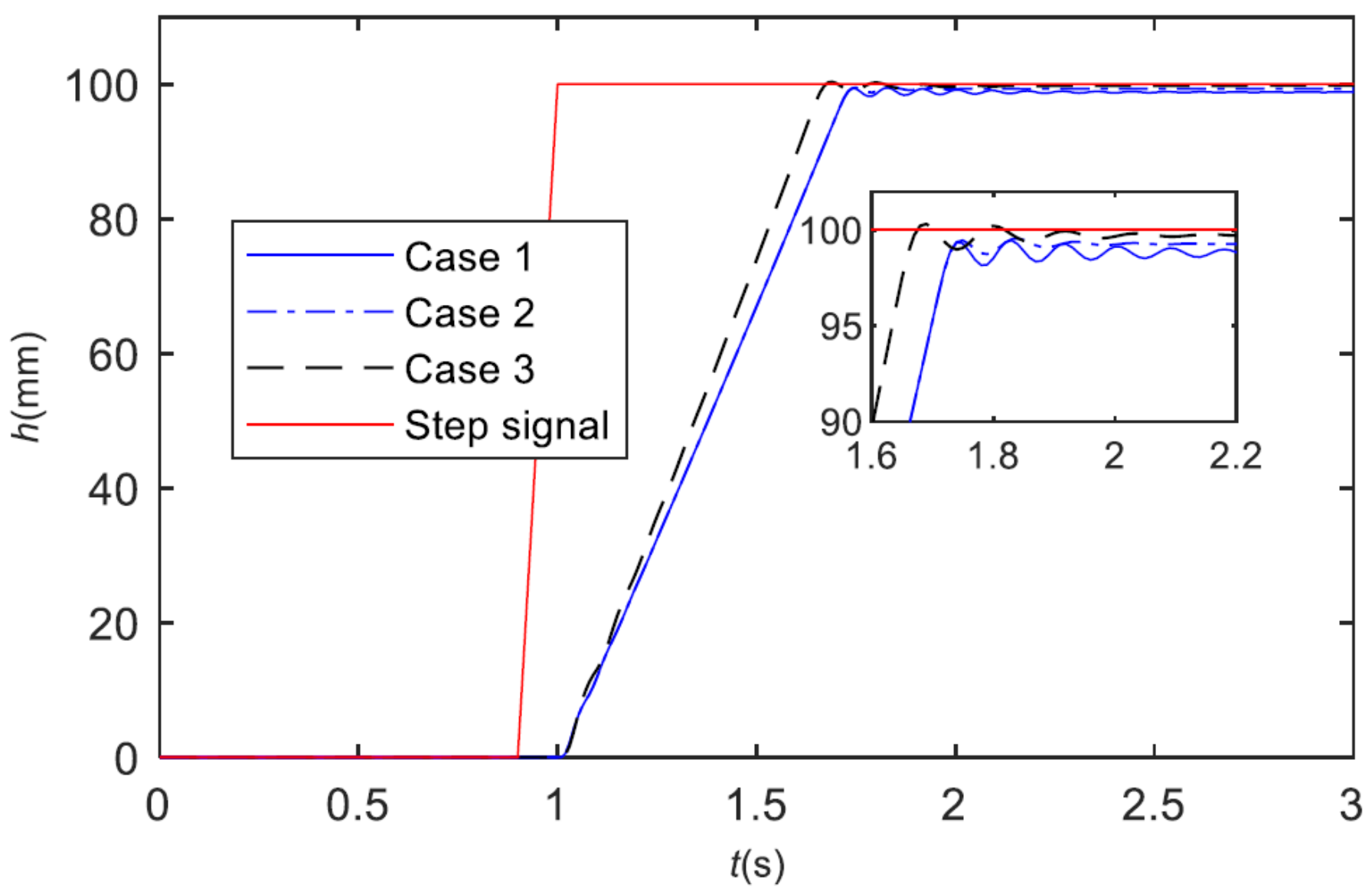

Figure 10

Comparison of response curves under the same height 


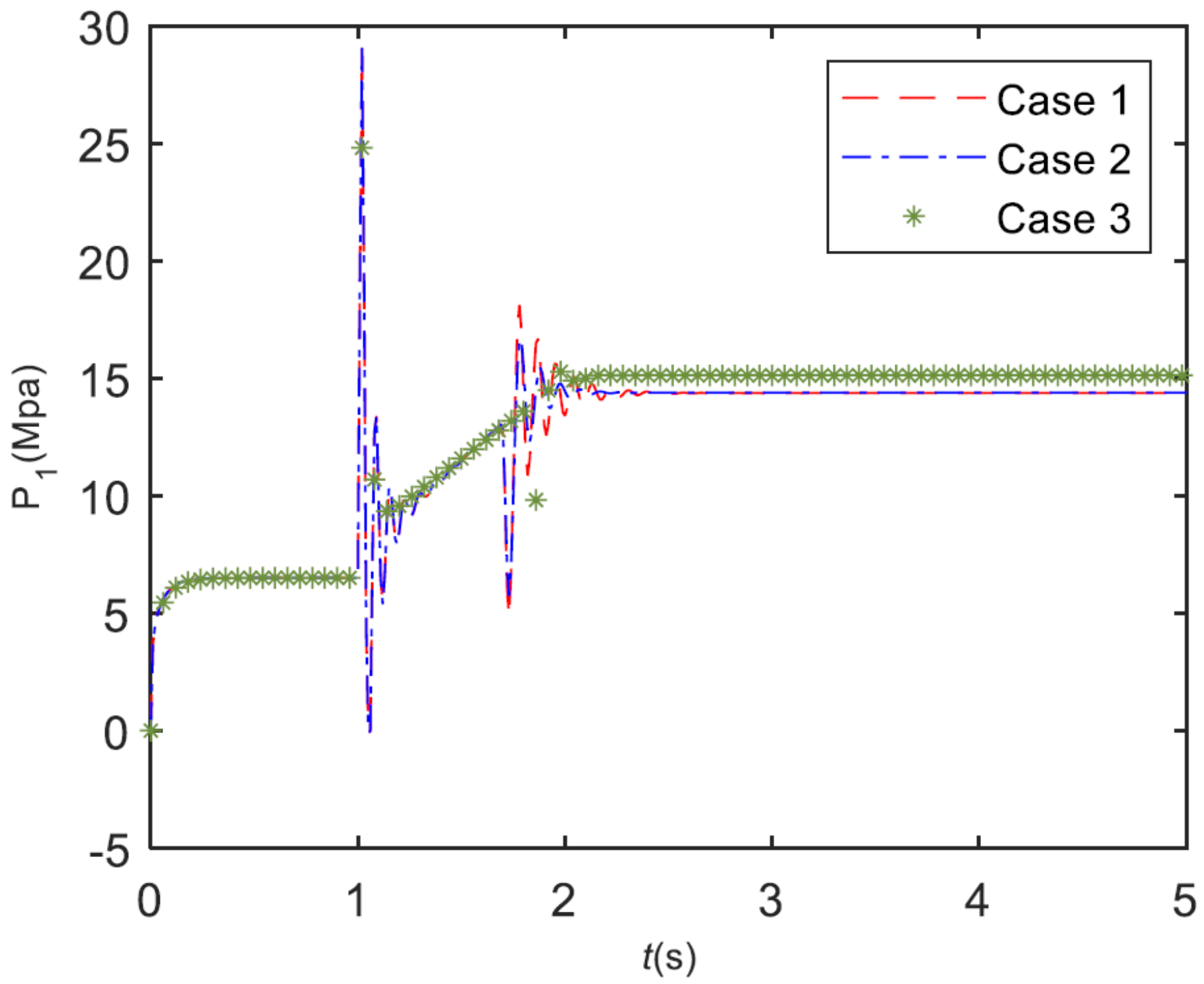

Figure 11

Pressure comparison of the three cases 


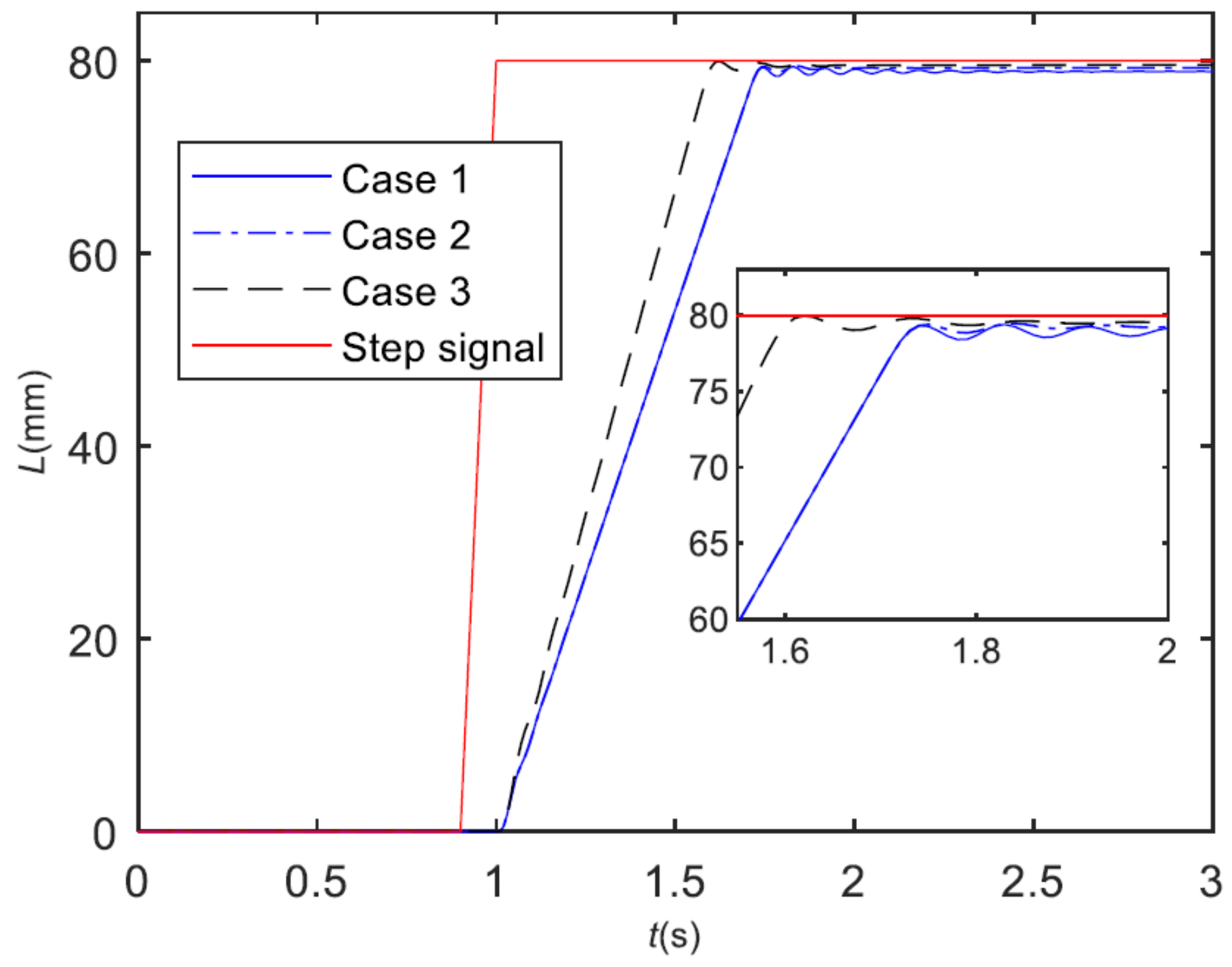

Figure 12

Comparison of displacement response 


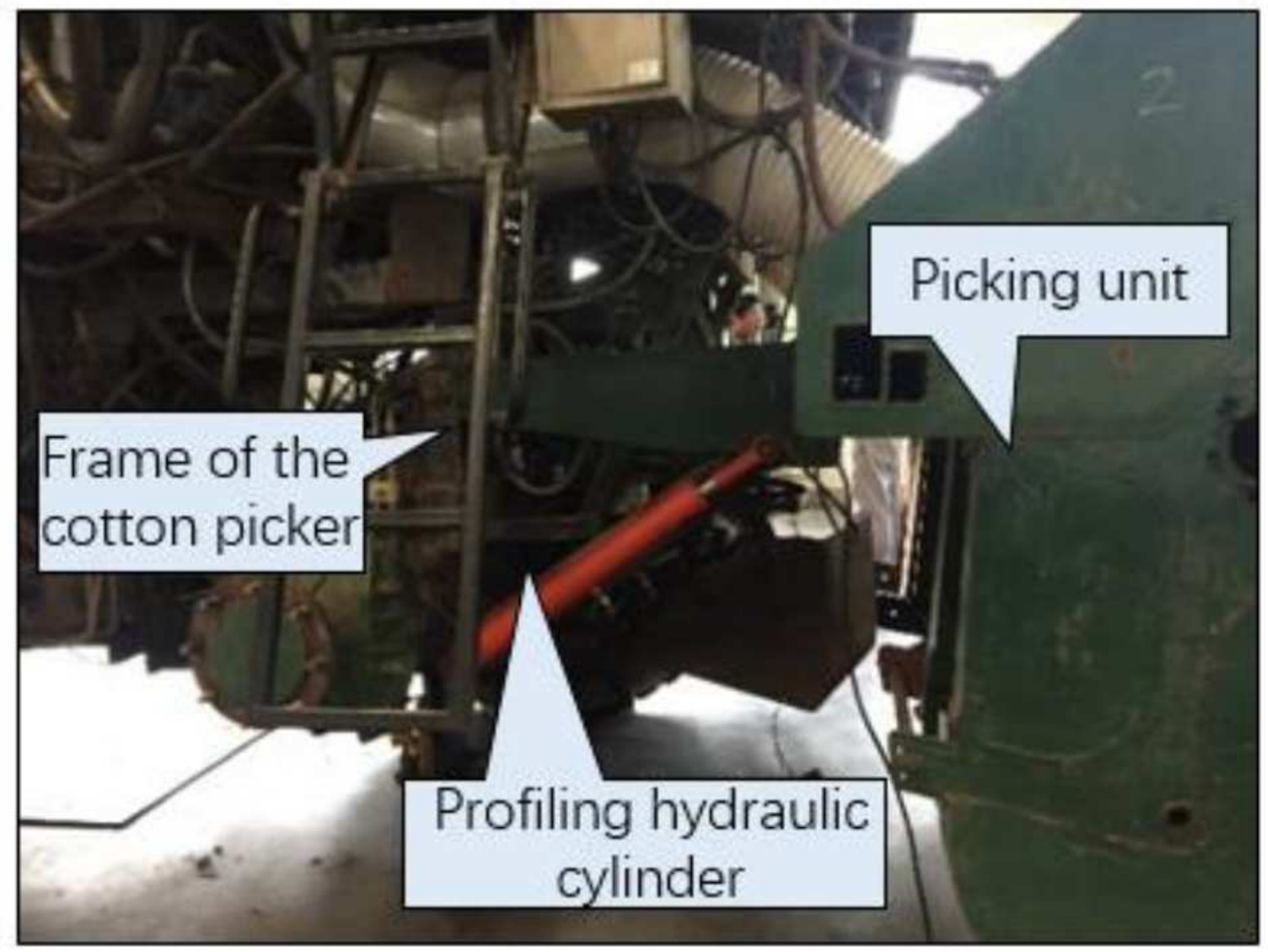

Figure 13

The height control system of spindle cotton picker 